\title{
Total synthesis of acaulide and acaulone $A$
}

Jun Hirabayashi ${ }^{1}$, Fumika Yakushiji ${ }^{1,2 *}$, Akira Katsuyama ${ }^{1,2}$, Satoshi Ichikawa ${ }^{1,2,3 *}$

${ }^{1}$ Faculty of Pharmaceutical Sciences, Hokkaido University, Kita-12, Nishi-6, Kita-ku, Sapporo 0600812, Japan

${ }^{2}$ Center for Research and Education on Drug Discovery, Faculty of Pharmaceutical Sciences, Hokkaido University, Kita-12, Nishi-6, Kita-ku, Sapporo 060-0812, Japan

${ }^{3}$ Global Station for Biosurfaces and Drug Discovery, Global Institution for Collaborative Research and Education (GI-CoRE), Hokkaido University, Kita-12, Nishi-6, Kita-ku, Sapporo 060-0812, Japan

\section{Contents}

1. General experimental methods $\mathrm{S} 1$

2. Preparation of compounds S2-S9

3. Examination of Michael addition S10-S11

4. HPLC analysis for determining the enantiopurity of $14 \quad \mathrm{~S} 12$

5. X-Ray crystallographic data of 7 S13-S15

6. Comparison of the NMR data of isolated and synthetic acaulide (1) S16

7. Comparison of the NMR data of isolated and synthetic acaulone A (2) S17

8. NMR spectrum of synthesized compounds S18-S30 


\section{General experimental methods}

All reactions except those carried out in aqueous phase were performed under argon atmosphere, unless otherwise noted. Materials were purchased from commercial suppliers and used without further purification, unless otherwise noted. Solvents $\left(\mathrm{CH}_{2} \mathrm{Cl}_{2}, \mathrm{MeCN}\right.$, DCE and pyridine) were distilled according to the standard protocol. All reactions requiring heating were heated by using SynFlex. Isolated yields were calculated by weighing products. The weight of the starting materials and the products were not calibrated. Analytical thin layer chromatography (TLC) was performed on Merck silica gel $60 \mathrm{~F}_{254}$ plates. Normal-phase column chromatography was performed on Merck silica gel $60(63-200 \mu \mathrm{m})$ or Kanto Chemical Silica Gel 60N (spherical, neutral, 63-210 $\mu \mathrm{m}$ ). Flash column chromatography was performed on Kanto Chemical Silica Gel 60N (spherical, neutral, 40-50 $\mu \mathrm{m}$ ). High flash column chromatography was performed on YAMAZEN Hi-FlashTM column silica gel $(40 \mu \mathrm{m})$ or Fuji Silysia Chromatorex MB/PSQ (50-200 $\mu \mathrm{m}) .{ }^{1} \mathrm{H}$ NMR were measured in $\mathrm{CDCl}_{3}$ or acetone- $d_{6}$ solution, and reported in parts per million $(\mathrm{ppm})$ relative to tetramethylsilane $(0.00 \mathrm{ppm})$ as internal standard or referenced to residual solvent peaks of acetone$d_{6}\left(2.05 \mathrm{ppm}\right.$ ) using JEOL ECS400, ECX400, ECA500, unless otherwise noted. ${ }^{13} \mathrm{C}$ NMR were measured in $\mathrm{CDCl}_{3}$ or acetone- $d_{6}$ solution, and referenced to residual solvent peaks of $\mathrm{CDCl}_{3}(77.16 \mathrm{ppm})$ or acetone- $d_{6}(29.84 \mathrm{ppm})$ using ECS400, ECX400, ECA500. Coupling constant $(J)$ was reported in hertz (Hz). Abbreviations of multiplicity were as follows; s: singlet, d: doublet, t: triplet, q: quartet, quin: quintet, sext: sextet, m: multiplet, br: broad. Data were presented as follows; chemical shift (multiplicity, integration, coupling constant). Assignment was based on ${ }^{1} \mathrm{H}-{ }^{1} \mathrm{H}$ COSY NMR spectra. Mass spectra were obtained on Thermo Fisher Scientific Q Exactive Orbitrap, Advion expression CMS or Waters ACQUITY UPLC Xevo G2 QTof. Optical rotation was measured on a Rudolph Research Analytical Autopol IV automatic polarimeter. X-ray crystallographic analysis was performed on Rigaku R-AXIS RAPID II. The compounds were named according to the IUPAC rules for naming or the literature that described isolation of the natural products acaulides. ${ }^{1)}$ When the compound was named according to the literature, numbering of atoms in the molecule was derived from the natural products. 


\section{Preparation of compounds}

\section{Allyl (2E,4S,5S)-4,5-epoxy-2-hexenoate (14)}

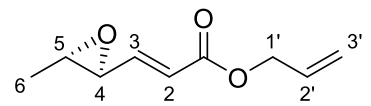

To a solution of trans-crotonaldehyde $(\mathbf{1 0})(4.11 \mathrm{~mL}, 50.0 \mathrm{mmol})$ in $\mathrm{CH}_{2} \mathrm{Cl}_{2}(160 \mathrm{~mL})$ was added $\quad(R)$ - $\alpha, \alpha$-bis[3,5-bis(trifluoromethyl)phenyl]-2-pyrrolidinemethanol trimethylsilyl ether (12) (2.99 g, $5.00 \mathrm{mmol}, 10 \mathrm{~mol} \%)$. After stirring at room temperature for $10 \mathrm{~min}, \mathrm{H}_{2} \mathrm{O}_{2}(30 \% \mathrm{w} / \mathrm{w}$ in water, $6.89 \mathrm{~mL}, 67.5 \mathrm{mmol}, 1.35$ equiv.) was added to the solution. The reaction was maintained at room temperature for $4 \mathrm{~h}$ to achieve full conversion of the aldehyde to an epoxy aldehyde. Upon completion of the reaction, the reaction mixture was diluted with $\mathrm{CH}_{2} \mathrm{Cl}_{2}(80 \mathrm{~mL})$, then to the solution was added allyl (triphenylphosphoranylidene)acetate (13) (27.0 g, $75.0 \mathrm{mmol}, 1.5$ equiv.) in a single portion. After stirring for $19 \mathrm{~h}$, water and brine were added to the reaction mixture. The organic phase was separated, dried over $\mathrm{Na}_{2} \mathrm{SO}_{4}$, filtered and concentrated in vacuo. The residue was purified by flash silica gel column chromatography $(\phi 6.3 \times 25$ $\mathrm{cm}$, AcOEt/hexane $=4-5 \%)$ to afford $14(4.43 \mathrm{~g}, 31.1 \mathrm{mmol}, 62 \%$, d.r. $>20: 1,95 \%$ ee $)$ as a yellow oil. The diastereomer ratio of $\mathbf{1 4}$ was determined by ${ }^{1} \mathrm{H}$ NMR, and the enantiopurity of $\mathbf{1 4}$ was determined by chiral HPLC (described in Table S3).

${ }^{1} \mathrm{H} \mathrm{NMR}\left(400 \mathrm{MHz}, \mathrm{CDCl}_{3}\right) \delta 6.71\left(\mathrm{dd}, 1 \mathrm{H}, \mathrm{H}-3, J_{3,2}=15.7, J_{3,4}=7.2 \mathrm{~Hz}\right), 6.16\left(\mathrm{~d}, 1 \mathrm{H}, \mathrm{H}-2, J_{2,3}=15.7, J_{2,4}=0.9\right.$ $\mathrm{Hz}), 5.94\left(\mathrm{ddt}, 1 \mathrm{H}, \mathrm{H}-2^{\prime}, J_{2^{\prime}, 3^{\prime}}=17.2, J_{2^{\prime}, 3^{\prime}}=10.3, J_{2^{\prime}, 1^{\prime}}=5.7 \mathrm{~Hz}\right), 5.34\left(\mathrm{dd}, 1 \mathrm{H}, \mathrm{H}-3^{\prime}, J_{3^{\prime}, 2^{\prime}}=17.2, J_{3^{\prime}, 1^{\prime}}=1.4 \mathrm{~Hz}\right), 5.25$ $\left(\mathrm{dd}, 1 \mathrm{H}, \mathrm{H}-3^{\prime}, J_{3^{\prime}, 2^{\prime}}=10.3, J_{3^{\prime}, 1^{\prime}}=1.4 \mathrm{~Hz}\right), 4.65\left(\mathrm{~d}, 2 \mathrm{H}, \mathrm{H}-1^{\prime}, J_{1^{\prime}, 2^{\prime}}=5.7, J_{1^{\prime}, 3^{\prime}}=1.4 \mathrm{~Hz}\right), 3.19\left(\mathrm{dd}, 1 \mathrm{H}, \mathrm{H}-4, J_{4,3}=7.2\right.$, $\left.J_{4,5}=1.8 \mathrm{~Hz}\right), 2.98\left(\mathrm{qd}, 1 \mathrm{H}, \mathrm{H}-5, J_{5,6}=5.2, J_{5,4}=1.8 \mathrm{~Hz}\right), 1.39\left(\mathrm{~d}, 3 \mathrm{H}, \mathrm{H}-6, J_{6,5}=5.2 \mathrm{~Hz}\right) ;{ }^{13} \mathrm{C} \mathrm{NMR}(100 \mathrm{MHz}$, $\left.\mathrm{CDCl}_{3}\right) \delta 165.4,145.3,132.1,123.4,118.5,65.4,57.6,57.3,17.7$; LRMS (ESI) $m / z:[\mathrm{M}+\mathrm{Na}]^{+}$191.9; HRMS (ESI) $m / z:[\mathrm{M}+\mathrm{Na}]^{+}$calcd for $\mathrm{C}_{9} \mathrm{H}_{12} \mathrm{O}_{3} \mathrm{Na} 191.0679$, found 191.0678; $[\alpha]^{21}{ }_{\mathrm{D}}=-8.17\left(c 1.03, \mathrm{CHCl}_{3}\right)$.

\section{Allyl (2E,4R,5S)-4-benzyloxy-5-hydroxy-2-hexenoate (8)}

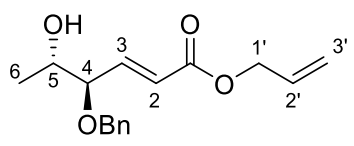

To a solution of ester $14(3.50 \mathrm{~g}, 20.8 \mathrm{mmol})$ and benzyl alcohol $(6.43 \mathrm{~mL}, 62.4$ mmol, 3.0 equiv.) in $\mathrm{CH}_{2} \mathrm{Cl}_{2}(60 \mathrm{~mL})$ was added $\mathrm{TfOH}(92.5 \mu \mathrm{L}, 1.04 \mathrm{mmol}, 5.0 \mathrm{~mol} \%)$ at $0{ }^{\circ} \mathrm{C}$, and the reaction mixture was allowed to warm to room temperature. After stirring for $2 \mathrm{~h}$, the reaction was quenched with $\mathrm{Et}_{3} \mathrm{~N}$ ( $23.1 \mathrm{~mL}, 166 \mathrm{mmol}, 8.0$ equiv.), and the mixture was treated with $\operatorname{TrCl}$ (29.0 g, $104 \mathrm{mmol}, 5.0$ equiv.) and DMAP (245 mg, $2.08 \mathrm{mmol}, 10 \mathrm{~mol} \%$ ) for $3.5 \mathrm{~h}$. Upon consumption of benzyl alcohol, water and $\mathrm{CH}_{2} \mathrm{Cl}_{2}$ were added to the reaction mixture. The organic phase was separated, dried over $\mathrm{Na}_{2} \mathrm{SO}_{4}$, filtered and concentrated in vacuo. The crude product was purified by flash silica gel column chromatography $(\phi 6.3 \times 25 \mathrm{~cm}, \mathrm{AcOEt} / \mathrm{hexane}=20-25 \%)$ to afford $8(4.15 \mathrm{~g}, 15.0 \mathrm{mmol}, 72 \%)$ as a pale-yellow oil.

${ }^{1} \mathrm{H}$ NMR $\left(400 \mathrm{MHz}, \mathrm{CDCl}_{3}\right) \delta$ 7.36-7.28 (m, 5H, Ph), $6.95\left(\mathrm{dd}, 1 \mathrm{H}, \mathrm{H}-3, J_{3,2}=15.8, J_{3,4}=6.7 \mathrm{~Hz}\right), 6.10(\mathrm{~d}, 1 \mathrm{H}, \mathrm{H}-2$, $\left.J_{2,3}=15.8, J_{2,4}=1.2 \mathrm{~Hz}\right), 5.97\left(\mathrm{ddt}, 1 \mathrm{H}, \mathrm{H}-2^{\prime}, J_{2^{\prime}, 3^{\prime}}=17.3, J_{2^{\prime}, 3^{\prime}}=10.4, J_{2^{\prime}, 1^{\prime}}=5.8 \mathrm{~Hz}\right), 5.36\left(\mathrm{dq}, 1 \mathrm{H}, \mathrm{H}-3^{\prime}, J_{3^{\prime}, 2^{\prime}}=17.3\right.$, $\left.J_{\mathrm{gem}}=J_{3^{\prime}, 1}=1.4 \mathrm{~Hz}\right), 5.27\left(\mathrm{dd}, 1 \mathrm{H}, \mathrm{H}-3^{\prime}, J_{3^{\prime}, 2^{\prime}}=10.4, J_{\mathrm{gem}}=J_{3^{\prime}, 1}=1.4 \mathrm{~Hz}\right), 4.67\left(\mathrm{dt}, 2 \mathrm{H}, \mathrm{H}-1^{\prime}, J_{1^{\prime}, 2^{\prime}}=5.8, J_{1^{\prime}, 3^{\prime}}=1.4\right.$ $\mathrm{Hz}), 4.66\left(\mathrm{~d}, 1 \mathrm{H}, \mathrm{PhCH}_{2}, J_{\mathrm{gem}}=11.7 \mathrm{~Hz}\right), 4.42\left(\mathrm{~d}, 1 \mathrm{H}, \mathrm{PhCH}_{2}, J_{\mathrm{gem}}=11.7 \mathrm{~Hz}\right), 3.96\left(\mathrm{qd}, 1 \mathrm{H}, \mathrm{H}-5, J_{5,6}=6.3, J_{5,4}=\right.$ $3.8 \mathrm{~Hz}$ ), $3.93\left(\mathrm{ddd}, 1 \mathrm{H}, \mathrm{H}-4, J_{4,3}=6.7, J_{4,5}=3.8, J_{4,2}=1.2 \mathrm{~Hz}\right.$ ), 2.17 (br s, $\left.1 \mathrm{H}, \mathrm{OH}\right) 1.16\left(\mathrm{~d}, 3 \mathrm{H}, \mathrm{H}-6, J_{6,5}=6.3 \mathrm{~Hz}\right.$ ); ${ }^{13} \mathrm{C}$ NMR $\left(100 \mathrm{MHz}, \mathrm{CDCl}_{3}\right) \delta 165.5,144.6,137.7,132.2,128.7(2 \mathrm{C}), 128.1,127.9(2 \mathrm{C}), 124.5,118.6,82.0,71.5$, 69.3, 65.5, 18.1; LRMS (ESI) $m / z$ : [M+Na $]^{+}$299.1; HRMS (ESI) $m / z$ : $[\mathrm{M}+\mathrm{Na}]^{+}$calcd for $\mathrm{C}_{16} \mathrm{H}_{20} \mathrm{O}_{4} \mathrm{Na} 299.1254$, 
found 299.1252; $[\alpha]^{21}{ }_{\mathrm{D}}=-64.34\left(c 0.96, \mathrm{CHCl}_{3}\right)$.

\section{tert-Butyl (6S)-6-(tert-butyldimethylsilyl)oxy-3-oxoheptanoate (11)}

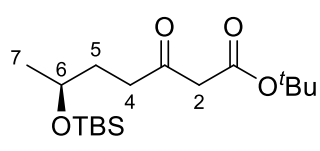

To a suspension of $\mathrm{NaH}$ (60\% in mineral oil, $4.16 \mathrm{~g}, 104 \mathrm{mmol}, 1.3$ equiv.) in THF (320 $\mathrm{mL}$ ) was slowly added $t$-butyl acetoacetate $\left(13.0 \mathrm{~mL}, 80.0 \mathrm{mmol}, 1.0\right.$ equiv.) at $0{ }^{\circ} \mathrm{C}$. After the mixture was stirred at $0{ }^{\circ} \mathrm{C}$ for $20 \mathrm{~min}, \mathrm{BuLi}(2.3 \mathrm{M}$ in cyclohexane, $41.6 \mathrm{~mL}, 95.7 \mathrm{mmol}$, 1.2 equiv.) was added to the solution. The resulting yellow solution was stirred for additional $20 \mathrm{~min}$, and $(S)$ propylene oxide $\left(8.72 \mathrm{~mL}, 125 \mathrm{mmol}, 1.6\right.$ equiv.) was added. After stirring at $0{ }^{\circ} \mathrm{C}$ for $9 \mathrm{~h}$, the reaction was quenched with sat. aq. $\mathrm{NH}_{4} \mathrm{Cl}$ at the same temperature, and the mixture was extracted with $\mathrm{Et}_{2} \mathrm{O}$. The combined organic phase was washed with brine, dried over $\mathrm{Na}_{2} \mathrm{SO}_{4}$, filtered and concentrated in vacuo. Then, the crude product was dissolved in THF $(80 \mathrm{~mL})$ at $0{ }^{\circ} \mathrm{C}$ followed by addition of $t$-BuOK $(1.0 \mathrm{M}$ in THF, $160 \mathrm{~mL}, 160 \mathrm{mmol}, 2.0$ equiv.) rapidly. After stirring for $15 \mathrm{~min}$, to the solution was added TBSCl (25.4 g, $169 \mathrm{mmol}, 2.1$ equiv.), and the reaction mixture was stirred overnight at room temperature. The reaction was quenched with sat. aq. $\mathrm{NH}_{4} \mathrm{Cl}$ and the aqueous phase was extracted with $\mathrm{Et}_{2} \mathrm{O}$. The organic phase was washed with brine, dried over $\mathrm{Na}_{2} \mathrm{SO}_{4}$, filtered and concentrated in vacuo. A solution of the residue in THF $(400 \mathrm{~mL})$ was treated with TBAF (1.0 M in THF, 96.0 mL, $96.0 \mathrm{mmol}, 1.2$ equiv.) at $0{ }^{\circ} \mathrm{C}$. After stirring for $5 \mathrm{~min}$, the reaction was quenched with sat. aq. $\mathrm{NH}_{4} \mathrm{Cl}$ and the mixture was extracted with AcOEt. The combined organic phase was washed with brine, dried over $\mathrm{Na}_{2} \mathrm{SO}_{4}$, and concentrated in vacuo. The crude product was purified by flash silica gel column chromatography $\left(\phi 6.3 \times 25 \mathrm{~cm}, \mathrm{Et}_{2} \mathrm{O} / \mathrm{h}\right.$ exane $\left.=5 \%\right)$ to afford 11 (15.3 g, $46.4 \mathrm{mmol}, 58 \%$ over 3 steps, keto form/enol form = 12/1 determined by ${ }^{1} \mathrm{H}$ NMR) as a pale-yellow oil, and $t$-butyl acetoacetate $(2.91 \mathrm{~g}, 18.4 \mathrm{mmol}, 23 \%)$ was recovered.

${ }^{1} \mathrm{H}$ NMR (keto form, $\left.\mathrm{CDCl}_{3}, 400 \mathrm{MHz}\right) \delta 3.84\left(\mathrm{dqd}, 1 \mathrm{H}, \mathrm{H}-6, J_{6,5}=7.3, J_{6,7}=6.2, J_{6,5}=4.4 \mathrm{~Hz}\right.$ ), $3.37(\mathrm{~d}, 1 \mathrm{H}, \mathrm{H}-2$, $\left.J_{\mathrm{gem}}=15.4 \mathrm{~Hz}\right), 3.33\left(\mathrm{~d}, 1 \mathrm{H}, \mathrm{H}-2, J_{\mathrm{gem}}=15.4 \mathrm{~Hz}\right), 2.63\left(\mathrm{ddd}, 1 \mathrm{H}, \mathrm{H}-4, J_{\mathrm{gem}}=17.5, J_{4,5}=8.9, J_{4,5}=5.8 \mathrm{~Hz}\right), 2.57$ $\left(\mathrm{ddd}, 1 \mathrm{H}, \mathrm{H}-4, J_{\mathrm{gem}}=17.5, J_{4,5}=8.8, J_{4,5}=6.3 \mathrm{~Hz}\right), 1.76\left(\mathrm{dddd}, 1 \mathrm{H}, \mathrm{H}-5, J_{\mathrm{gem}}=14.1, J_{5,4}=8.9, J_{5,4}=6.3, J_{5,6}=4.4\right.$ $\mathrm{Hz}$ ), 1.65 (dddd, $\left.1 \mathrm{H}, \mathrm{H}-5, J_{\mathrm{gem}}=14.1, J_{5,4}=8.8, J_{5,6}=7.3, J_{5,4}=5.8 \mathrm{~Hz}\right), 1.47\left(\mathrm{~s}, 9 \mathrm{H}, \mathrm{O}-{ }^{t} \mathrm{Bu}\right), 1.13\left(\mathrm{~d}, 3 \mathrm{H}, \mathrm{H}-7, J_{7,6}\right.$ $=6.2 \mathrm{~Hz}), 0.88\left(\mathrm{~s}, 9 \mathrm{H},{ }^{t} \mathrm{Bu}-\mathrm{Si}\right), 0.05$ (s, 3H, Me-Si), 0.04 (s, 3H, Me-Si); ${ }^{13} \mathrm{C}$ NMR $\delta$ 203.5, 166.6, 82.0, 67.5, 50.9, 39.0, 33.0, 28.1(3C), 26.0(3C), 23.8, 18.2, -4.3, -4.6; LRMS (ESI) $m / z$ : [M+Na] ${ }^{+} 353.0$; HRMS (ESI) $m / z:[\mathrm{M}+\mathrm{Na}]^{+}$ calcd for $\mathrm{C}_{17} \mathrm{H}_{34} \mathrm{NaO}_{4} \mathrm{Si} 353.2119$, found 353.2131; $[\alpha]^{22}{ }_{\mathrm{D}}=+17.99\left(c 0.60, \mathrm{CHCl}_{3}\right)$.

\section{tert-Butyl (2E,7S)-(tert-butyldimethylsilyl)oxy-4-oxo-2-octenoate (15)}<smiles>CCCCC(=O)C=CC(=O)CC(C)C</smiles>

To a solution of $\mathrm{ZnEt}_{2}$ (1.08 $\mathrm{M}$ in hexane, $69.9 \mathrm{~mL}, 75.5 \mathrm{mmol}$, 5.0 equiv.) in $\mathrm{CH}_{2} \mathrm{Cl}_{2}$ $(450 \mathrm{~mL})$ was added $\mathrm{CH}_{2} \mathrm{I}_{2}(6.39 \mathrm{~mL}, 79.3 \mathrm{mmol}, 5.5$ equiv. $)$ at $0{ }^{\circ} \mathrm{C}$. After stirring for 30 min, a solution of 11 ( $4.99 \mathrm{~g}, 15.1 \mathrm{mmol}, 1.0$ equiv.) in $\mathrm{CH}_{2} \mathrm{Cl}_{2}(50 \mathrm{~mL})$ was added to the mixture, which was stirred at the same temperature for $2 \mathrm{~h}$. Iodine (19.2 g, $75.5 \mathrm{~g}, 5.0$ equiv.) was added in two portions to the reaction mixture, and the mixture was allowed to warm to room temperature and stirred for $10 \mathrm{~min}$ until a violet color persisted. To the solution was added sat. aq. $\mathrm{Na}_{2} \mathrm{~S}_{2} \mathrm{O}_{3}$ and the mixture was stirred until the violet color had disappeared. 1,8-Diazabicyclo[5.4.0]undec-7-ene (22.6 mL, $151 \mathrm{mmol}, 10$ equiv.) and sat. aq. potassium sodium tartrate $(200 \mathrm{~mL})$ were added to the solution, and the biphasic layers were continued stirring vigorously for $1 \mathrm{~h}$. Then, to the reaction mixture was added brine, and the organic phase was separated. The aqueous phase was 
extracted with $\mathrm{CH}_{2} \mathrm{Cl}_{2}$, and the combined organic phase was washed with $1 \mathrm{M}$ aq. $\mathrm{HCl}$, sat. aq. $\mathrm{NaHCO}_{3}$ and brine, dried over $\mathrm{Na}_{2} \mathrm{SO}_{4}$, filtered and concentrated in vacuo. The crude product was purified by flash silica gel column chromatography $\left(\phi 6.7 \times 25 \mathrm{~cm}, \mathrm{Et}_{2} \mathrm{O} /\right.$ hexane $\left.=7 \%\right)$ to afford $15(4.26 \mathrm{~g}, 12.4 \mathrm{mmol}, 82 \%)$ as a yellow oil.

${ }^{1} \mathrm{H}$ NMR $\left(400 \mathrm{MHz}, \mathrm{CDCl}_{3}\right) \delta 6.96$ (d, 1H, H-3, $\left.J_{3,2}=16.0 \mathrm{~Hz}\right), 6.59$ (d, 1H, H-2, $\left.J_{2,3}=16.0 \mathrm{~Hz}\right), 3.87$ (dqd, $1 \mathrm{H}, \mathrm{H}-$ $\left.7, J_{7,6}=7.3, J_{7,8}=6.2, J_{7,6}=4.4 \mathrm{~Hz}\right), 2.73\left(\mathrm{ddd}, 1 \mathrm{H}, \mathrm{H}-5, J_{\mathrm{gem}}=17.8, J_{5,6}=8.8, J_{5,6}=6.1 \mathrm{~Hz}\right), 2.67$ (ddd, $1 \mathrm{H}, \mathrm{H}-5$, $\left.J_{\mathrm{gem}}=17.8, J_{5,6}=8.5, J_{5,6}=6.5 \mathrm{~Hz}\right), 1.79\left(\mathrm{dddd}, 1 \mathrm{H}, \mathrm{H}-6, J_{\mathrm{gem}}=13.9, J_{6,5}=8.8, J_{6,5}=6.5, J_{6,7}=4.4 \mathrm{~Hz}\right), 1.68(\mathrm{dddd}$, $\left.1 \mathrm{H}, \mathrm{H}-6, J_{\mathrm{gem}}=13.9, J_{6,5}=8.5, J_{6,7}=7.3, J_{6,5}=6.1 \mathrm{~Hz}\right), 1.51\left(\mathrm{~s}, 9 \mathrm{H}, \mathrm{O}-{ }^{t} \mathrm{Bu}\right), 1.14\left(\mathrm{~d}, 3 \mathrm{H}, \mathrm{H}-8, J_{8,7}=6.2 \mathrm{~Hz}\right), 0.88$ (s, 9H, ${ }^{t} \mathrm{Bu}-\mathrm{Si}$ ), 0.05 (s, 3H, Me-Si), 0.03 (s, 3H, Me-Si); ${ }^{13} \mathrm{C} \mathrm{NMR}\left(100 \mathrm{MHz}, \mathrm{CDCl}_{3}\right) \delta 202.3,164.9,138.8,132.8$, 82.1, 67.5, 37.4, 33.2, 28.1(3C), 26.0(3C), 23.8, 18.2, -4.3, -4.6; LRMS (ESI) $m / z$ : [M+Na] 353.0 ; HRMS (ESI) $m / z:[\mathrm{M}+\mathrm{H}]^{+}$calcd for $\mathrm{C}_{18} \mathrm{H}_{34} \mathrm{O}_{4} \mathrm{Si} 365.2300$, found 365.2304; $[\alpha]^{20}{ }_{\mathrm{D}}=+13.65\left(c 0.60, \mathrm{CHCl}_{3}\right)$.

$\left(1^{\prime} S, 2^{\prime} R, 3^{\prime} E\right)$-5'-Allyoxy-2'-benzyloxy-5'-oxohex-3'-en-1'-yl (2E,7S)-4,7-bis[(tert-butyldimethylsily)oxy]octa-

\section{2,4-dienoate (16)}

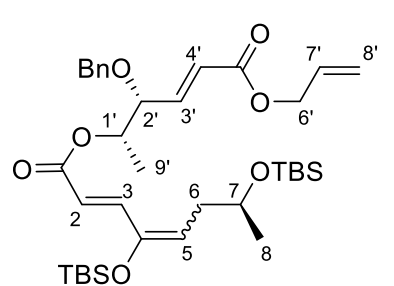

To a solution of compound $15(5.79 \mathrm{~g}, 16.9 \mathrm{mmol})$ in $\mathrm{CH}_{2} \mathrm{Cl}_{2}(160 \mathrm{~mL})$ were added 2,6-lutidine (7.28 mL, $62.5 \mathrm{mmol}, 3.7$ equiv.) and TBSOTf (13.5 mL, $59.1 \mathrm{mmol}, 3.5$ equiv.) at $0{ }^{\circ} \mathrm{C}$, and the reaction mixture was allowed to warm to room temperature. After stirring for $3.5 \mathrm{~h}$, the reaction was quenched with water. The organic phase was separated and washed with $1 \mathrm{M}$ aq. $\mathrm{HCl}$, sat. aq. $\mathrm{NaHCO}_{3}$ and brine, dried over $\mathrm{Na}_{2} \mathrm{SO}_{4}$,

filtered and concentrated in vacuo. A solution of the crude product in $\mathrm{MeOH}(160 \mathrm{~mL})$ was treated with $\mathrm{K}_{2} \mathrm{CO}_{3}(3.5$ g, 25.4 mmol, 1.5 equiv.) at room temperature. After stirring for $15 \mathrm{~min}, \mathrm{CH}_{2} \mathrm{Cl}_{2}$ and sat. aq. $\mathrm{NH}_{4} \mathrm{Cl}$ were added to the mixture. The organic phase was separated and washed with brine, dried over $\mathrm{Na}_{2} \mathrm{SO}_{4}$, filtered and concentrated in vacuo. Then, the residue was co-evaporated with toluene at $40{ }^{\circ} \mathrm{C}$ three times and dried under reduced pressure to afford a carboxylic acid as a crude product.

A solution of $N, N$-dimethyl-4-aminopyridine (345 mg, $2.82 \mathrm{mmol}, 20 \mathrm{~mol} \%$ ) and (+)-10-camphorsulfonic acid (CSA) (328 mg, $1.41 \mathrm{mmol}, 10 \mathrm{~mol} \%$ ) in $\mathrm{CH}_{2} \mathrm{Cl}_{2}(50 \mathrm{~mL})$ was stirred at room temperature for $20 \mathrm{~min}$. To the mixture was added a solution of the prepared carboxylic acid (16.9 mmol) and alcohol 8 (3.90 g, $14.1 \mathrm{mmol}, 0.83$ equiv.) in $\mathrm{CH}_{2} \mathrm{Cl}_{2}(20 \mathrm{~mL})$ at $0{ }^{\circ} \mathrm{C}$, followed by addition of DCC (4.37 g, $21.2 \mathrm{mmol}, 1.5$ equiv.). The reaction mixture was warmed to room temperature and stirred for $10 \mathrm{~h}$. The resulting white suspension was filtered, and the filtrate was washed with $1 \mathrm{M} \mathrm{aq}$. $\mathrm{HCl}$, sat. aq. $\mathrm{NaHCO}_{3}$ and brine, dried over $\mathrm{Na}_{2} \mathrm{SO}_{4}$, filtered and concentrated in vacuo. The crude product was purified by flash silica gel column chromatography $\left(\phi 6.7 \times 26 \mathrm{~cm}, \mathrm{Et}_{2} \mathrm{O} / \mathrm{hexane}=10-14 \%\right)$ to afford $16(7.99 \mathrm{~g}, 12.1 \mathrm{mmol}, 86 \%$ over 3 steps, $E / Z=10 / 9$ or 9/10) as a pale-yellow oil.

${ }^{1} \mathrm{H}$ NMR (E/Z mixture, $\left.400 \mathrm{MHz}, \mathrm{CDCl}_{3}\right) \delta 7.46\left(\mathrm{~d}, 1 \mathrm{H}, \mathrm{H}-3, J_{3,2}=15.2 \mathrm{~Hz}\right), 7.35-7.28(\mathrm{~m}, 10 \mathrm{H}, \mathrm{Ph}), 7.09(\mathrm{~d}, 1 \mathrm{H}$, $\left.\mathrm{H}-3, J_{3,2}=15.7 \mathrm{~Hz}\right), 6.90\left(\mathrm{dd}, 1 \mathrm{H}, \mathrm{H}-3^{\prime}, J_{3^{\prime}, 4^{\prime}}=15.5, J_{3^{\prime}, 2^{\prime}}=5.9 \mathrm{~Hz}\right), 6.89\left(\mathrm{dd}, 1 \mathrm{H}, \mathrm{H}-3^{\prime}, J_{3^{\prime}, 4^{\prime}}=15.5, J_{3^{\prime}, 2^{\prime}}=5.9 \mathrm{~Hz}\right)$, $6.14\left(\mathrm{dd}, 1 \mathrm{H}, \mathrm{H}-4^{\prime}, J_{4^{\prime}, 3^{\prime}}=15.5, J_{4^{\prime}, 2^{\prime}}=1.4 \mathrm{~Hz}\right), 6.13\left(\mathrm{dd}, 1 \mathrm{H}, \mathrm{H}-4^{\prime}, J_{4^{\prime}, 3^{\prime}}=15.5, J_{4^{\prime}, 2^{\prime}}=1.4 \mathrm{~Hz}\right), 6.12\left(\mathrm{~d}, 1 \mathrm{H}, \mathrm{H}-2, J_{2,3}=\right.$ $15.2 \mathrm{~Hz}$ ), 5.95 (ddt, $\left.2 \mathrm{H}, \mathrm{H}-7^{\prime}, J_{7^{\prime}, 8^{\prime}}=17.1, J_{7^{\prime}, 8^{\prime}}=10.4, J_{7^{\prime}, 6^{\prime}}=5.8 \mathrm{~Hz}\right), 5.92\left(\mathrm{~d}, 1 \mathrm{H}, \mathrm{H}-2, J_{2,3}=15.7 \mathrm{~Hz}\right), 5.34(\mathrm{dd}, 2 \mathrm{H}$, H-8', $\left.J_{8^{\prime}, 7^{\prime}}=17.1, J_{8^{\prime}, 6^{\prime}}=1.4 \mathrm{~Hz}\right), 5.28\left(\mathrm{t}, 2 \mathrm{H}, \mathrm{H}-5, J_{5,6}=6.3 \mathrm{~Hz}\right), 5.26\left(\mathrm{dd}, 2 \mathrm{H}, \mathrm{H}-8^{\prime}, J_{8^{\prime}, 7^{\prime}}=10.4, J_{8^{\prime}, 6^{\prime}}=1.4 \mathrm{~Hz}\right), 5.11$ (qd, 1H, H-1', $\left.J_{1^{\prime}, 9^{\prime}}=6.3, J_{1^{\prime}, 2^{\prime}}=4.1 \mathrm{~Hz}\right), 5.10\left(\mathrm{qd}, 1 \mathrm{H}, \mathrm{H}-1^{\prime}, J_{1^{\prime}, 9^{\prime}}=6.3, J_{1^{\prime}, 2^{\prime}}=4.1 \mathrm{~Hz}\right), 4.66\left(\mathrm{~d}, 4 \mathrm{H}, \mathrm{H}-6^{\prime}, J_{6^{\prime}, 7^{\prime}}=5.8\right.$ $\mathrm{Hz}), 4.64\left(\mathrm{~d}, 1 \mathrm{H}, \mathrm{PhCH}_{2}, J_{\text {gem }}=12.3 \mathrm{~Hz}\right), 4.63\left(\mathrm{~d}, 1 \mathrm{H}, \mathrm{PhCH}_{2}, J_{\text {gem }}=11.6 \mathrm{~Hz}\right), 4.52\left(\mathrm{~d}, 1 \mathrm{H}, \mathrm{PhCH}_{2}, J_{\text {gem }}=11.6 \mathrm{~Hz}\right)$, 
$4.51\left(\mathrm{~d}, 1 \mathrm{H}, \mathrm{PhCH}_{2}, J_{\mathrm{gem}}=12.3 \mathrm{~Hz}\right), 4.14\left(\mathrm{ddd}, 1 \mathrm{H}, \mathrm{H}-2^{\prime}, J_{2^{\prime}, 3^{\prime}}=5.9, J_{2^{\prime}, 1^{\prime}}=4.1, J_{2^{\prime}, 4^{\prime}}=1.4 \mathrm{~Hz}\right), 4.14\left(\mathrm{ddd}, 1 \mathrm{H}, \mathrm{H}-2^{\prime}\right.$, $\left.J_{2^{\prime}, 3^{\prime}}=5.9, J_{2^{\prime}, 1}=4.1, J_{2^{\prime}, 4^{\prime}}=1.4 \mathrm{~Hz}\right), 3.87\left(\mathrm{sext}, 1 \mathrm{H}, \mathrm{H}-7, J_{7,6}=J_{7,8}=6.0 \mathrm{~Hz}\right), 3.85$ (sext, $1 \mathrm{H}, \mathrm{H}-7, J_{7,6}=J_{7,8}=6.0$ $\mathrm{Hz}), 2.31\left(\mathrm{dd}, 1 \mathrm{H}, \mathrm{H}-6, J_{6,5}=7.3, J_{6,7}=6.0 \mathrm{~Hz}\right), 2.29\left(\mathrm{dd}, 1 \mathrm{H}, \mathrm{H}-6, J_{6,5}=7.3, J_{6,7}=6.0 \mathrm{~Hz}\right), 1.29\left(\mathrm{~d}, 3 \mathrm{H}, \mathrm{H}-9^{\prime}, J_{9^{\prime}, 1^{\prime}}\right.$ $=6.3 \mathrm{~Hz}), 1.28\left(\mathrm{~d}, 3 \mathrm{H}, \mathrm{H}-9^{\prime}, J_{9^{\prime}, 1^{\prime}}=6.3 \mathrm{~Hz}\right), 1.13\left(\mathrm{~d}, 3 \mathrm{H}, \mathrm{H}-8, J_{8,7}=6.0 \mathrm{~Hz}\right), 1.11$ (d, 3H, H-8, J8, $\left.=6.0 \mathrm{~Hz}\right), 1.00$ (s, $9 \mathrm{H},{ }^{t} \mathrm{Bu}-\mathrm{Si}$ ), 0.98 (s, 9H, ${ }^{t} \mathrm{Bu}-\mathrm{Si}$ ), 0.88 (s, 9H, ${ }^{t} \mathrm{Bu}-\mathrm{Si}$ ), 0.87 (s, 9H, ${ }^{t} \mathrm{Bu}-\mathrm{Si}$ ), 0.16 (s, 6H, 2Me-Si), 0.12 (s, 3H, Me-Si), 0.11 (s, 3H, Me-Si), 0.05 (s, 12H, 2Me-Si); $\left.{ }^{13} \mathrm{C} \mathrm{NMR} \mathrm{(E/Z} \mathrm{mixture,} 100 \mathrm{MHz}, \mathrm{CDCl}_{3}\right) \delta 166.7,166.6,165.6(2 \mathrm{C})$, $148.3,147.8,144.8(2 \mathrm{C}), 144.2,137.9,137.7,132.2(2 \mathrm{C}), 128.6(4 \mathrm{C}), 127.9(2 \mathrm{C}), 127.8(4 \mathrm{C}), 123.9,123.8,121.5$, 118.5(3C), 117.1, 116.6, 79.7, 79.6, 71.9(2C), 71.7, 71.5, 68.4, 68.1, 65.4(2C), 36.94, 36.88, 26.1(3C), 26.0(9C), 23.9, $23.5,18.5,18.4,18.22,18.16,15.2,15.1,-3.5(2 \mathrm{C}),-4.25,-4.27,-4.3,-4.4,-4.57,-4.60$; LRMS (ESI) $m / z$ : $[\mathrm{M}+\mathrm{Na}]^{+} 680.9$; HRMS (ESI) $m / z$ : $[\mathrm{M}+\mathrm{H}]^{+}$calcd for $\mathrm{C}_{36} \mathrm{H}_{59} \mathrm{O}_{7} \mathrm{Si}_{2} 659.3794$, found 659.3774; $[\alpha]^{20}{ }_{\mathrm{D}}=-11.87(c$ 0.50, $\left.\mathrm{CHCl}_{3}\right)$.

\section{4-O-Benzyl-10-ketoacaudiol (7)}

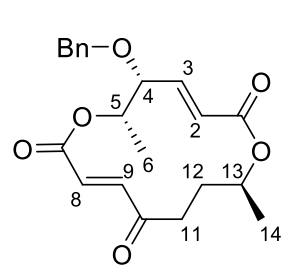

A solution of ester $16(1.00 \mathrm{~g}, 1.52 \mathrm{mmol})$ in $\mathrm{MeCN}(8 \mathrm{~mL})$ was treated with morpholine (660 $\mu \mathrm{L}, 7.58 \mathrm{mmol}, 5.0$ equiv.) and $\mathrm{Pd}\left(\mathrm{PPh}_{3}\right)_{4}(175 \mathrm{mg}, 0.152 \mathrm{mmol}, 10 \mathrm{~mol} \%)$ at $25{ }^{\circ} \mathrm{C}$. After stirring for $1.5 \mathrm{~h}$, the reaction was quenched with SCAVENGER SH silica, and the mixture was stirred for $1 \mathrm{~h}$. The resulting red suspension was filtered and the filtrate was concentrated in vacuo. The residue was diluted with AcOEt and the mixture was washed with

$1 \mathrm{M} a q$. $\mathrm{HCl}$ and brine, dried over $\mathrm{Na}_{2} \mathrm{SO}_{4}$, filtered and concentrated in vacuo. A solution of the crude product in $\mathrm{MeCN}(8 \mathrm{~mL})$ was treated with aq. $\mathrm{HF}(48 \% \mathrm{w} / \mathrm{w}$ in water, $1.15 \mathrm{~mL}, 15.2 \mathrm{mmol}, 10$ equiv.) at room temperature for $30 \mathrm{~min}$. Upon completion of the reaction, the reaction was quenched with TMSOH (2.85 mL, $30.4 \mathrm{mmol}, 20$ equiv.), and the mixture was stirred for $30 \mathrm{~min}$. After concentration of the mixture in vacuo, a solution of the residue in THF $(8 \mathrm{~mL})$ was treated with TBAF (1.0 M in THF, $1.82 \mathrm{~mL}, 1.82 \mathrm{mmol}, 1.2$ equiv.) for $5 \mathrm{~min}$. The reaction was quenched with sat. aq. $\mathrm{NH}_{4} \mathrm{Cl}$, and the resulting mixture was extracted with $\mathrm{CH}_{2} \mathrm{Cl}_{2}$. The organic phase was washed with brine, dried over $\mathrm{Na}_{2} \mathrm{SO}_{4}$, filtered and concentrated in vacuo. Then, a solution of the crude product in $\mathrm{CH}_{2} \mathrm{Cl}_{2}(760 \mathrm{~mL})$ was treated with MNBA (785 mg, $2.28 \mathrm{mmol}, 1.5$ equiv.) and DMAP (557 mg, $4.56 \mathrm{mmol}, 3.0$ equiv.). After the reaction mixture was stirred at $30^{\circ} \mathrm{C}$ for $11 \mathrm{~h}$, the solvent was removed in vacuo. The residue was diluted with AcOEt and the organic phase was washed with $1 \mathrm{Maq}$. $\mathrm{HCl}$, sat. aq. $\mathrm{NaHCO}_{3}$ and brine, dried over $\mathrm{Na}_{2} \mathrm{SO}_{4}$, filtered and concentrated in vacuo. The crude product was purified by flash silica gel column chromatography $(\phi 2.8 \times 20 \mathrm{~cm}$, AcOEt/hexane $=10-23 \%)$ to afford 7 (254 mg, $0.682 \mathrm{mmol}, 45 \%$ over 4 steps) as a colorless prism. The single crystal of 7 was obtained by recrystallization from $\mathrm{CHCl}_{3}$ /hexane. X-Ray crystallographic data are described in Figure $\mathrm{S} 1$ and Tables S4-S5.

mp: $115-119{ }^{\circ} \mathrm{C} ;{ }^{1} \mathrm{H}$ NMR $\left(400 \mathrm{MHz}, \mathrm{CDCl}_{3}\right) \delta$ 7.38-7.28 (m, 5H, Ph), 6.88 (d, 1H, H-9, J9,8 $\left.=15.5 \mathrm{~Hz}\right), 6.68(\mathrm{dd}$, $\left.1 \mathrm{H}, \mathrm{H}-3, J_{3,2}=16.0, J_{3,4}=9.0 \mathrm{~Hz}\right), 6.62\left(\mathrm{~d}, 1 \mathrm{H}, \mathrm{H}-8, J_{8,9}=15.5 \mathrm{~Hz}\right), 5.82\left(\mathrm{~d}, 1 \mathrm{H}, \mathrm{H}-2, J_{2,3}=16.0 \mathrm{~Hz}\right), 5.10(\mathrm{dq}, 1 \mathrm{H}$, $\left.\mathrm{H}-5, J_{5,4}=9.0, J_{5,6}=6.3 \mathrm{~Hz}\right), 5.06\left(\mathrm{dqd}, 1 \mathrm{H}, \mathrm{H}-13, J_{13,12}=9.0, J_{13,14}=6.3, J_{13,12}=3.5 \mathrm{~Hz}\right), 4.65\left(\mathrm{~d}, 1 \mathrm{H}, \mathrm{PhCH}_{2}, J_{\text {gem }}\right.$ $=11.7 \mathrm{~Hz}), 4.35\left(\mathrm{~d}, 1 \mathrm{H}, \mathrm{PhCH}_{2}, J_{\mathrm{gem}}=11.7 \mathrm{~Hz}\right), 3.72\left(\mathrm{t}, 1 \mathrm{H}, \mathrm{H}-4, J_{4,3}=J_{4,5}=9.0 \mathrm{~Hz}\right), 2.66\left(\mathrm{ddd}, 1 \mathrm{H}, \mathrm{H}-11, J_{\text {gem }}=\right.$ $\left.13.1, J_{11,12}=9.0, J_{11,12}=3.5 \mathrm{~Hz}\right), 2.56\left(\mathrm{ddd}, 1 \mathrm{H}, \mathrm{H}-11, J_{\text {gem }}=13.1, J_{11,12}=9.1, J_{11,12}=3.5 \mathrm{~Hz}\right), 2.12(\mathrm{ddt}, 1 \mathrm{H}, \mathrm{H}-12$, $\left.J_{\mathrm{gem}}=15.3, J_{12,11}=9.1, J_{12,11}=J_{12,13}=3.5 \mathrm{~Hz}\right), 1.98\left(\mathrm{dtd}, 1 \mathrm{H}, \mathrm{H}-12, J_{\mathrm{gem}}=15.3, J_{12,11}=J_{12,13}=9.0, J_{12,11}=3.5 \mathrm{~Hz}\right)$, 
$1.45\left(\mathrm{~d}, 3 \mathrm{H}, \mathrm{H}-6, J_{6,5}=6.3 \mathrm{~Hz}\right), 1.26\left(\mathrm{~d}, 3 \mathrm{H}, \mathrm{H}-14, J_{14,13}=6.3 \mathrm{~Hz}\right) ;{ }^{13} \mathrm{C} \mathrm{NMR}\left(125 \mathrm{MHz}, \mathrm{CDCl}_{3}\right) \delta 200.1,166.3$, 165.0, 146.4, 139.1, 137.2, 131.6, 128.6(2C), 128.2, 128.1(2C), 127.7, 82.9, 72.11, 72.1, 71.5, 39.1, 32.5, 19.5, 17.7; LRMS (ESI) $m / z$ : $[\mathrm{M}+\mathrm{Na}]^{+}$395.0; HRMS (ESI) $m / z$ : $[\mathrm{M}+\mathrm{Na}]^{+}$calcd for $\mathrm{C}_{21} \mathrm{H}_{24} \mathrm{O}_{6} \mathrm{Na}$ 395.1466, found 395.1460; $[\alpha]^{20}{ }_{\mathrm{D}}=-86.39\left(c 0.45, \mathrm{CHCl}_{3}\right)$.

\section{0-Keto-acaudiol A (3)}

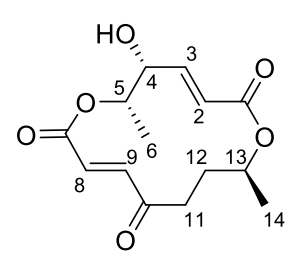

To a solution of $7(10.0 \mathrm{mg}, 26.8 \mu \mathrm{mol})$ in 1,2-dichloroethane $(90 \mu \mathrm{L})$ and $0.1 \mathrm{M}$ phosphate buffer ( $\mathrm{pH} 7.0)(10 \mu \mathrm{L})$ was added DDQ $(24.3 \mathrm{mg}, 107 \mu \mathrm{mol}, 4.0$ equiv.). The reaction mixture was heated to $80^{\circ} \mathrm{C}$ and stirred for $3 \mathrm{~h}$. Upon completion of the reaction, the mixture was cooled to $0{ }^{\circ} \mathrm{C}$ and poured into sat. aq. $\mathrm{NaHCO}_{3}$, and the resulting mixture was extracted with $\mathrm{CH}_{2} \mathrm{Cl}_{2}$. The combined organic phase was washed with brine, dried over $\mathrm{Na}_{2} \mathrm{SO}_{4}$, filtered and concentrated in vacuo. The residue was purified by silica gel column chromatography $(\phi 1.0 \times 11 \mathrm{~cm}, \mathrm{AcOEt} / \mathrm{hexane}$ $=40 \%)$ to afford $3(4.1 \mathrm{mg}, 14.5 \mu \mathrm{mol}, 54 \%)$ as a white powder

${ }^{1} \mathrm{H}$ NMR $\left(500 \mathrm{MHz}, \mathrm{CDCl}_{3}\right) \delta 6.89$ (d, $\left.1 \mathrm{H}, \mathrm{H}-9, J_{9,8}=15.6 \mathrm{~Hz}\right), 6.64\left(\mathrm{~d}, 1 \mathrm{H}, \mathrm{H}-8, J_{8,9}=15.6 \mathrm{~Hz}\right), 6.61(\mathrm{dd}, 1 \mathrm{H}, \mathrm{H}-$ $\left.3, J_{3,2}=15.8, J_{3,4}=8.8 \mathrm{~Hz}\right), 5.76\left(\mathrm{dd}, 1 \mathrm{H}, \mathrm{H}-2, J_{2,3}=15.8, J_{2,4}=1.2 \mathrm{~Hz}\right), 5.05\left(\mathrm{dqd}, 1 \mathrm{H}, \mathrm{H}-13, J_{13,12}=9.0, J_{13,14}=\right.$ $\left.6.3, J_{13,12}=2.6 \mathrm{~Hz}\right), 5.02\left(\mathrm{dq}, 1 \mathrm{H}, \mathrm{H}-5, J_{5,4}=8.8, J_{5,6}=6.3 \mathrm{~Hz}\right), 3.72\left(\mathrm{t}, 1 \mathrm{H}, \mathrm{H}-4, J_{4,3}=J_{4,5}=8.8 \mathrm{~Hz}\right), 2.66(\mathrm{ddd}, 1 \mathrm{H}$, $\left.\mathrm{H}-11, J_{\mathrm{gem}}=13.1, J_{11,12}=9.0, J_{11,12}=3.3 \mathrm{~Hz}\right), 2.56\left(\mathrm{ddd}, 1 \mathrm{H}, \mathrm{H}-11, J_{\mathrm{gem}}=13.1, J_{11,12}=9.0, J_{11,12}=3.3 \mathrm{~Hz}\right), 2.11(\mathrm{br}$ s, $1 \mathrm{H}, \mathrm{OH}), 2.11\left(\mathrm{ddt}, 1 \mathrm{H}, \mathrm{H}-12, J_{\mathrm{gem}}=15.5, J_{12,11}=9.0, J_{12,11}=J_{12,13}=3.3 \mathrm{~Hz}\right), 1.98\left(\mathrm{dtd}, 1 \mathrm{H}, \mathrm{H}-12, J_{\mathrm{gem}}=15.5\right.$, $\left.J_{12,11}=J_{12,13}=9.0, J_{12,11}=3.3 \mathrm{~Hz}\right), 1.44\left(\mathrm{~d}, 3 \mathrm{H}, \mathrm{H}-6, J_{6,5}=6.3 \mathrm{~Hz}\right), 1.26\left(\mathrm{~d}, 3 \mathrm{H}, \mathrm{H}-14, J_{14,13}=6.3 \mathrm{~Hz}\right) ;{ }^{13} \mathrm{C} \mathrm{NMR}$ $\left(100 \mathrm{MHz}, \mathrm{CDCl}_{3}\right) \delta 200.1,166.5,165.3,146.2,139.1,131.6,125.8,73.2,71.6,39.3,32.5,19.5,17.4$ (The solvent peaks overlap with a peak of the sample.); LRMS (ESI) $m / z$ : $[\mathrm{M}+\mathrm{Na}]^{+} 305.0$; HRMS (ESI) $m / z$ : $[\mathrm{M}+\mathrm{H}]^{+}$calcd for $\mathrm{C}_{14} \mathrm{H}_{19} \mathrm{O}_{6} 283.1177$, found 283.1188; $[\alpha]^{21}{ }_{\mathrm{D}}=+50.78(c 0.25, \mathrm{MeOH})$.

\section{Protected acaulide (18) and protected acaulone A (19)}

Optimized procedure for stepwise Michael addition

A solution of 6-methyldihydropyran-2,4-dione (4) $(1.72 \mathrm{mg}, 13.4 \mu \mathrm{mol})$ in $\mathrm{MeCN}(100 \mu \mathrm{L})$ was treated with $\mathrm{Cs}_{2} \mathrm{CO}_{3}(4.37 \mathrm{mg}, 13.4 \mu \mathrm{mol}, 1.0$ equiv.) at room temperature for $15 \mathrm{~min}$. Then, compound 7 (5.0 mg, $13.4 \mu \mathrm{mol}, 1.0$ equiv.) was added to the mixture that was stirred for $5 \mathrm{~min}$. The reaction was quenched with $1 \mathrm{Maq}$. $\mathrm{HCl}$, and the mixture was diluted with $\mathrm{CH}_{2} \mathrm{Cl}_{2}$. The organic phase was separated and concentrated in vacuo. To the solution of the crude product in 1,2-dichloroethane ( $25 \mu \mathrm{L}$ ) was added $N$-methylmorpholine ( $2.2 \mu \mathrm{L}, 20.1 \mu$ mol, 1.5 equiv.). After stirring at room temperature for $15 \mathrm{~min}, 7(5.0 \mathrm{mg}, 13.4 \mu \mathrm{mol}, 1.0$ equiv.) was added to the resulting mixture. After a further $66 \mathrm{~h}$ stirring at $25^{\circ} \mathrm{C}$, the reaction was quenched with $1 \mathrm{Maq}$. $\mathrm{HCl}$ and the mixture was diluted with $\mathrm{CH}_{2} \mathrm{Cl}_{2}$. The organic phase was separated and concentrated in vacuo. The residue was purified by preparative TLC $(20 \times 20$ $\mathrm{cm}, \mathrm{AcOEt} / \mathrm{hexane}=45 \%)$ to afford $\mathbf{1 8}(6.1 \mathrm{mg}, 7.0 \mu \mathrm{mol}, 53 \%$ over $2 \mathrm{steps})$ as a colorless foam and $19(0.4 \mathrm{mg}$, $0.85 \mu \mathrm{mol}, 7 \%$ over 2 steps) as a colorless oil.

\section{General procedure for one-pot Michael addition}

To a solution of 6-methyldihydropyran-2,4-dione (4) in solvent ( $0.5 \mathrm{M})$ were added base (2.5 equiv.) and additive 
( 0.5 equiv.), and the mixture was stirred at room temperature for $10 \mathrm{~min}$. The compound 7 (2.0 equiv.) was added to the solution at the same temperature in a single portion, then the reaction mixture was allowed to warm to desired temperature. After stirring for the preset time, the reaction was quenched with $1 \mathrm{Maq}$. $\mathrm{HCl}$. The mixture was diluted with $\mathrm{CH}_{2} \mathrm{Cl}_{2}$ and the organic phase was separated, dried over $\mathrm{Na}_{2} \mathrm{SO}_{4}$, filtered and concentrated in vacuo. The residue was purified by preparative TLC $(20 \times 20 \mathrm{~cm}$, AcOEt/hexane $=45 \%)$ to afford $\mathbf{1 8}$ and $\mathbf{1 9}$.

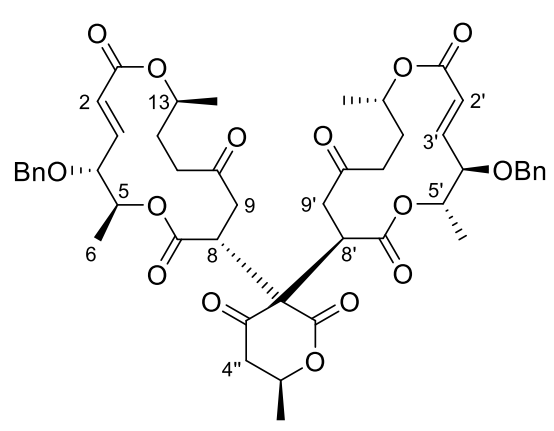

Protected acaulide (18): ${ }^{1} \mathrm{H}$ NMR $\left(500 \mathrm{MHz}\right.$, acetone- $\left.d_{6}\right) \delta$ 7.40-7.29 (m, $10 \mathrm{H}, \mathrm{Ph}), 6.67$ (dd, 1H, H-3, $\left.J_{3,2}=16.0, J_{3,4}=5.7 \mathrm{~Hz}\right), 6.61\left(\mathrm{dd}, 1 \mathrm{H}, \mathrm{H}-3, J_{3,2}\right.$ $\left.=15.8, J_{3,4}=4.9 \mathrm{~Hz}\right), 5.89\left(\mathrm{~d}, 1 \mathrm{H}, \mathrm{H}-2, J_{2,3}=16.0, J_{2,4}=1.2 \mathrm{~Hz}\right), 5.85(\mathrm{dd}$, $\left.1 \mathrm{H}, \mathrm{H}-2, J_{2,3}=15.8, J_{2,4}=1.2 \mathrm{~Hz}\right), 4.90\left(\mathrm{dqd}, 1 \mathrm{H}, \mathrm{H}-13, J_{13,12}=9.2, J_{13,14}=\right.$ $\left.6.3, J_{13,12}=3.2 \mathrm{~Hz}\right), 4.83\left(\mathrm{dqd}, 1 \mathrm{H}, \mathrm{H}-13, J_{13,12}=9.3, J_{13,14}=6.3, J_{13,12}=3.4\right.$ $\mathrm{Hz}$ ), 4.76 (dqd, $\left.1 \mathrm{H}, \mathrm{H}-5^{\prime \prime}, J_{5^{\prime \prime}, 4^{\prime \prime}}=12.6, J_{5^{\prime \prime}, 6^{\prime \prime}}=6.3, J_{5^{\prime \prime}, 4^{\prime \prime}}=2.9 \mathrm{~Hz}\right), 4.64$ (d, $2 \mathrm{H}$, $\left.\mathrm{PhCH}_{2}, J_{\text {gem }}=11.5 \mathrm{~Hz}\right), 4.59\left(\mathrm{dq}, 1 \mathrm{H}, \mathrm{H}-5, J_{5,4}=9.2, J_{5,6}=6.3 \mathrm{~Hz}\right), 4.45(\mathrm{~d}$, $\left.1 \mathrm{H}, \mathrm{PhCH}_{2}, J_{\mathrm{gem}}=11.5 \mathrm{~Hz}\right), 4.44\left(\mathrm{~d}, 1 \mathrm{H}, \mathrm{PhCH}_{2}, J_{\mathrm{gem}}=11.5 \mathrm{~Hz}\right), 4.41(\mathrm{dq}$, $\left.1 \mathrm{H}, \mathrm{H}-5, J_{5,4}=9.2, J_{5,6}=6.3 \mathrm{~Hz}\right), 4.04\left(\mathrm{ddd}, 1 \mathrm{H}, \mathrm{H}-4, J_{4,5}=9.2, J_{4,3}=5.7, J_{4,2}=1.2 \mathrm{~Hz}\right), 4.00\left(\mathrm{ddd}, 1 \mathrm{H}, \mathrm{H}-4, J_{4,5}=\right.$ $\left.9.2, J_{4,3}=4.9, J_{4,2}=1.2 \mathrm{~Hz}\right), 3.93\left(\mathrm{t}, 1 \mathrm{H}, \mathrm{H}-8, J_{8,9}=4.5 \mathrm{~Hz}\right), 3.56\left(\mathrm{dd}, 1 \mathrm{H}, \mathrm{H}-8, J_{8,9}=6.9, J_{8,9}=3.7 \mathrm{~Hz}\right), 3.51(\mathrm{dd}$, $\left.1 \mathrm{H}, \mathrm{H}-9, J_{\mathrm{gem}}=20.0, J_{9,8}=4.5 \mathrm{~Hz}\right), 3.10\left(\mathrm{dd}, 1 \mathrm{H}, \mathrm{H}-4 ", J_{\mathrm{gem}}=15.8, J_{4^{\prime \prime}, 5^{\prime \prime}}=12.6 \mathrm{~Hz}\right), 2.94\left(\mathrm{dd}, 1 \mathrm{H}, \mathrm{H}-9, J_{\mathrm{gem}}=19.5\right.$, $\left.J_{9,8}=3.7 \mathrm{~Hz}\right), 2.68\left(\mathrm{dd}, 1 \mathrm{H}, \mathrm{H}-9, J_{\mathrm{gem}}=19.5, J_{9,8}=6.9 \mathrm{~Hz}\right), 2.66\left(\mathrm{dd}, 1 \mathrm{H}, \mathrm{H}-11, J_{\mathrm{gem}}=17.6, J_{11,12}=9.2 \mathrm{~Hz}\right), 2.65$ $\left(\mathrm{dd}, 1 \mathrm{H}, \mathrm{H}-9, J_{\mathrm{gem}}=20.0, J_{9,8}=4.5 \mathrm{~Hz}\right), 2.58\left(\mathrm{ddd}, 1 \mathrm{H}, \mathrm{H}-11, J_{\mathrm{gem}}=17.3, J_{11,12}=8.2, J_{11,12}=2.3 \mathrm{~Hz}\right), 2.56(\mathrm{dd}, 1 \mathrm{H}$, H-4", $\left.J_{\text {gem }}=15.8, J_{4^{\prime \prime}, 5^{\prime \prime}}=2.9 \mathrm{~Hz}\right), 2.51\left(\mathrm{ddd}, 1 \mathrm{H}, \mathrm{H}-11, J_{\mathrm{gem}}=17.3, J_{11,12}=9.5, J_{11,12}=1.7 \mathrm{~Hz}\right), 2.41(\mathrm{dd}, 1 \mathrm{H}, \mathrm{H}-11$, $\left.J_{\text {gem }}=17.6, J_{11,12}=10.0 \mathrm{~Hz}\right), 2.18-2.13(\mathrm{~m}, 1 \mathrm{H}, \mathrm{H}-12), 2.11-2.03(\mathrm{~m}, 1 \mathrm{H}, \mathrm{H}-12), 1.88-1.82(\mathrm{~m}, 2 \mathrm{H}, \mathrm{H}-12), 1.38(\mathrm{~d}$, $\left.3 \mathrm{H}, \mathrm{H}-6 ", J_{6 ", 5 "}=6.3 \mathrm{~Hz}\right), 1.32\left(\mathrm{~d}, 3 \mathrm{H}, \mathrm{H}-6, J_{6,5}=6.3 \mathrm{~Hz}\right), 1.28\left(\mathrm{~d}, 3 \mathrm{H}, \mathrm{H}-6, J_{6,5}=6.3 \mathrm{~Hz}\right), 1.25\left(\mathrm{~d}, 3 \mathrm{H}, \mathrm{H}-14, J_{14,13}=\right.$ $6.3 \mathrm{~Hz}), 1.24$ (d, 3H, H-14, $\left.J_{14,13}=6.3 \mathrm{~Hz}\right) ;{ }^{13} \mathrm{C}$ NMR $\left(125 \mathrm{MHz}\right.$, acetone- $\left.d_{6}\right) \delta 206.3,206.0,205.7,174.1,173.0$, 171.8, 165.2, 165.1, 146.5, 146.3, 138.8(2C), 129.2(4C), 128.9(4C), 128.6(2C), 124.1, 123.3, 80.9, 80.5, 74.9, 74.7, 72.62, 72.56, 72.1, 72.0, 71.8, 57.2, 46.4, 46.1, 43.6, 41.3, 40.4, 39.3, 39.1, 29.2, 28.5, 21.8, 20.3, 20.2, 18.4, 18.3; LRMS (ESI) $m / z$ : $[\mathrm{M}+\mathrm{Na}]^{+}$895.3; HRMS (ESI) $\mathrm{m} / z$ : $[\mathrm{M}+\mathrm{H}]^{+}$calcd for $\mathrm{C}_{48} \mathrm{H}_{57} \mathrm{O}_{15}$ 873.3692, found 873.3712; $[\alpha]^{26}{ }_{\mathrm{D}}$ $=+2.52\left(c 0.74, \mathrm{CHCl}_{3}\right)$.

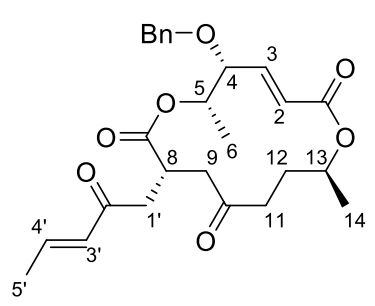

Protected acaulone A (19): ${ }^{1} \mathrm{H} \mathrm{NMR}\left(500 \mathrm{MHz}, \mathrm{CDCl}_{3}\right) \delta$ 7.37-7.29 (m, 5H, Ph), 6.84 $\left(\mathrm{dq}, 1 \mathrm{H}, \mathrm{H}-4^{\prime}, J_{4^{\prime}, 3^{\prime}}=15.7, J_{4^{\prime}, 5^{\prime}}=6.8 \mathrm{~Hz}\right), 6.74\left(\mathrm{dd}, 1 \mathrm{H}, \mathrm{H}-3, J_{3,2}=16.0, J_{3,4}=5.5 \mathrm{~Hz}\right)$, $6.08\left(\mathrm{dq}, 1 \mathrm{H}, \mathrm{H}-3^{\prime}, J_{3^{\prime}, 4^{\prime}}=15.7, J_{3^{\prime}, 5^{\prime}}=1.3 \mathrm{~Hz}\right), 5.99\left(\mathrm{dd}, 1 \mathrm{H}, \mathrm{H}-2, J_{2,3}=16.0, J_{2,4}=1.2\right.$ $\mathrm{Hz}), 4.95\left(\mathrm{dqd}, 1 \mathrm{H}, \mathrm{H}-13, J_{13,12}=8.7, J_{13,14}=6.3, J_{13,12}=3.4 \mathrm{~Hz}\right), 4.68(\mathrm{dq}, 1 \mathrm{H}, \mathrm{H}-5$, $\left.J_{5,4}=8.3, J_{5,6}=6.3 \mathrm{~Hz}\right), 4.66\left(\mathrm{~d}, 1 \mathrm{H}, \mathrm{PhCH}_{2}, J_{\mathrm{gem}}=11.8 \mathrm{~Hz}\right), 4.36\left(\mathrm{~d}, 1 \mathrm{H}, \mathrm{PhCH}_{2}, J_{\mathrm{gem}}\right.$ $=11.8 \mathrm{~Hz}), 3.91\left(\mathrm{ddd}, 1 \mathrm{H}, \mathrm{H}-4, J_{4,5}=8.3, J_{4,3}=5.5, J_{4,2}=1.2 \mathrm{~Hz}\right), 3.39-3.34(\mathrm{~m}, 1 \mathrm{H}$, H-8), $3.00\left(\mathrm{dd}, 1 \mathrm{H}, \mathrm{H}-1^{\prime}, J_{\text {gem }}=17.5, J_{1^{\prime}, 8}=7.8 \mathrm{~Hz}\right), 2.75\left(\mathrm{dd}, 1 \mathrm{H}, \mathrm{H}-9, J_{\text {gem }}=18.8, J_{9,8}=6.0 \mathrm{~Hz}\right), 2.63(\mathrm{dd}, 1 \mathrm{H}, \mathrm{H}-$ $\left.9, J_{\mathrm{gem}}=18.8, J_{9,8}=4.6 \mathrm{~Hz}\right), 2.53\left(\mathrm{dd}, 1 \mathrm{H}, \mathrm{H}-11, J_{\mathrm{gem}}=17.5, J_{11,12}=8.7 \mathrm{~Hz}\right), 2.52\left(\mathrm{dd}, 1 \mathrm{H}, \mathrm{H}-1^{\prime}, J_{\mathrm{gem}}=17.5, J_{1^{\prime}, 8}=\right.$ $6.6 \mathrm{~Hz}$ ), $2.30\left(\mathrm{dd}, 1 \mathrm{H}, \mathrm{H}-11, J_{\mathrm{gem}}=17.5, J_{11,12}=9.2 \mathrm{~Hz}\right), 2.05\left(\mathrm{dtd}, 1 \mathrm{H}, \mathrm{H}-12, J_{\mathrm{gem}}=14.6, J_{12,11}=J_{12,13}=8.7, J_{12,11}\right.$ $=1.2 \mathrm{~Hz}), 1.94\left(\mathrm{dddd}, 1 \mathrm{H}, \mathrm{H}-12, J_{\mathrm{gem}}=14.6, J_{12,11}=9.2, J_{12,13}=3.4, J_{12,11}=1.2 \mathrm{~Hz}\right), 1.88\left(\mathrm{dd}, 3 \mathrm{H}, \mathrm{H}-5^{\prime}, J_{5^{\prime}, 4^{\prime}}=6.8\right.$, 
$\left.J_{5^{\prime}, 3^{\prime}}=1.3 \mathrm{~Hz}\right), 1.36\left(\mathrm{~d}, 3 \mathrm{H}, \mathrm{H}-6, J_{6,5}=6.3 \mathrm{~Hz}\right), 1.28\left(\mathrm{~d}, 3 \mathrm{H}, \mathrm{H}-14, J_{14,13}=6.3 \mathrm{~Hz}\right) ;{ }^{13} \mathrm{C} \mathrm{NMR}\left(125 \mathrm{MHz}, \mathrm{CDCl}_{3}\right) \delta$ 205.9, 197.6, 173.9, 165.2 146.3, 143.7, 137.4, 131.7, 128.6(2C), 128.2(3C), 123.3, 79.9, 72.9, 72.0, 71.2, 44.6, 40.9, 38.7, 34.8, 28.3, 20.0, 18.5, 18.3; LRMS (ESI) $\mathrm{m} / z$ : $[\mathrm{M}+\mathrm{Na}]^{+} 479.1$; HRMS (ESI) $\mathrm{m} / z$ : $[\mathrm{M}+\mathrm{Na}]^{+}$calcd for $\mathrm{C}_{26} \mathrm{H}_{32} \mathrm{O}_{7} \mathrm{Na} 479.2041$, found 479.2046; $[\alpha]^{20}{ }_{\mathrm{D}}=-34.31\left(c 0.27, \mathrm{CHCl}_{3}\right)$.

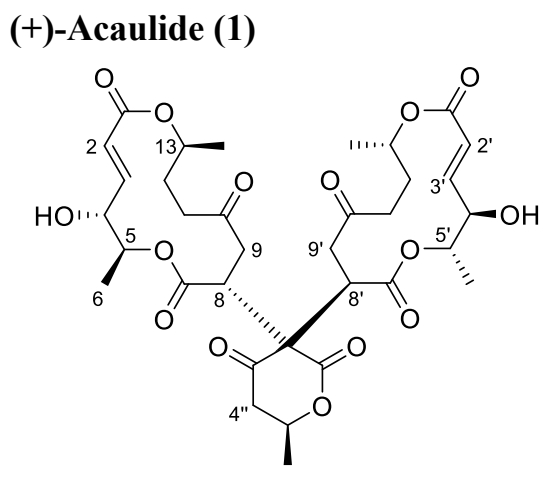

To a solution of $\mathbf{1 8}(5.0 \mathrm{mg}, 5.73 \mu \mathrm{mol})$ in 1,2-dichloroethane $(450 \mu \mathrm{L})$ and $0.1 \mathrm{M}$ phosphate buffer (pH 7.0) $(50 \mu \mathrm{L})$ was added DDQ (12.9 mg, 57.3 $\mu \mathrm{mol}, 10$ equiv.). The reaction mixture was warmed to $80^{\circ} \mathrm{C}$ and stirred for $20 \mathrm{~h}$. Upon completion of the reaction, the mixture was cooled to $0{ }^{\circ} \mathrm{C}$, poured into sat. aq. $\mathrm{NaHCO}_{3}$, and extracted with $\mathrm{CH}_{2} \mathrm{Cl}_{2}$. The combined organic phase was washed with brine, dried over $\mathrm{Na}_{2} \mathrm{SO}_{4}$ and concentrated in vacuo. The residue was purified by silica gel column chromatography $(\phi 1.1 \times 10 \mathrm{~cm}$, AcOEt/hexane $=50-60 \%)$ to afford $1(3.4 \mathrm{mg}, 4.9 \mu \mathrm{mol}, 86 \%)$ as a white foam.

${ }^{1} \mathrm{H}$ NMR (500 MHz, acetone- $\left.d_{6}\right) \delta 6.77$ (dd, $\left.1 \mathrm{H}, \mathrm{H}-3, J_{3,2}=15.5, J_{3,4}=4.6 \mathrm{~Hz}\right), 6.70$ (dd, $1 \mathrm{H}, \mathrm{H}-3, J_{3,4}=16.0, J_{3,4}=4.0$ $\mathrm{Hz}), 5.84\left(\mathrm{dd}, 1 \mathrm{H}, \mathrm{H}-2, J_{2,3}=15.5, J_{2,4}=1.7 \mathrm{~Hz}\right), 5.82\left(\mathrm{dd}, 1 \mathrm{H}, \mathrm{H}-2, J_{2,3}=16.0, J_{2,4}=1.7 \mathrm{~Hz}\right), 4.83\left(\mathrm{dqd}, 1 \mathrm{H}, \mathrm{H}-13, J_{13,12}\right.$ $\left.=9.7, J_{13,14}=6.3, J_{13,12}=3.3 \mathrm{~Hz}\right), 4.80-4.75(\mathrm{~m}, 4 \mathrm{H}, \mathrm{OH}, \mathrm{H}-13,5 "), 4.47$ (dq, $\left.1 \mathrm{H}, \mathrm{H}-5, J_{5,4}=9.5, J_{5,6}=6.3 \mathrm{~Hz}\right), 4.30$ (dq, $\left.1 \mathrm{H}, \mathrm{H}-5, J_{5,4}=9.3, J_{5,6}=6.0 \mathrm{~Hz}\right), 4.19\left(\mathrm{ddd}, 1 \mathrm{H}, \mathrm{H}-4, J_{4,5}=9.3, J_{4,3}=4.6, J_{4,2}=1.7 \mathrm{~Hz}\right), 4.15\left(\mathrm{ddd}, 1 \mathrm{H}, \mathrm{H}-4, J_{4,5}=9.5, J_{4,3}\right.$ $\left.=4.6, J_{4,2}=1.7 \mathrm{~Hz}\right), 3.97\left(\mathrm{t}, 1 \mathrm{H}, \mathrm{H}-8, J_{8,9}=4.6 \mathrm{~Hz}\right), 3.62\left(\mathrm{dd}, 1 \mathrm{H}, \mathrm{H}-8, J_{8,9}=6.6, J_{8,9}=3.6 \mathrm{~Hz}\right), 3.50\left(\mathrm{dd}, 1 \mathrm{H}, \mathrm{H}-9, J_{\mathrm{gem}}=\right.$ $\left.19.9, J_{9,8}=4.6 \mathrm{~Hz}\right), 3.05$ (dd, 1H, H-4", $\left.J_{\mathrm{gem}}=15.8, J_{4^{\prime \prime}, 5^{\prime \prime}}=12.6 \mathrm{~Hz}\right), 3.01\left(\mathrm{dd}, 1 \mathrm{H}, \mathrm{H}-9, J_{\mathrm{gem}}=19.1, J_{9,8}=3.4 \mathrm{~Hz}\right), 2.72$ $\left(\mathrm{dd}, 1 \mathrm{H}, \mathrm{H}-9, J_{\mathrm{gem}}=19.1, J_{9,8}=6.9 \mathrm{~Hz}\right), 2.70\left(\mathrm{dd}, 1 \mathrm{H}, \mathrm{H}-9, J_{\mathrm{gem}}=19.9, J_{9,8}=4.6 \mathrm{~Hz}\right), 2.70\left(\mathrm{dd}, 1 \mathrm{H}, \mathrm{H}-11, J_{\mathrm{gem}}=18.9\right.$, $\left.J_{11,12}=8.6 \mathrm{~Hz}\right), 2.62\left(\mathrm{ddd}, 1 \mathrm{H}, \mathrm{H}-11, J_{\text {gem }}=18.0, J_{11,12}=9.2, J_{11,12}=1.7 \mathrm{~Hz}\right), 2.58\left(\mathrm{dd}, 1 \mathrm{H}, \mathrm{H}-4 ", J_{\text {gem }}=15.8, J_{4^{\prime \prime}, 5^{\prime \prime}}=\right.$ $2.9 \mathrm{~Hz}$ ), $2.52\left(\mathrm{ddd}, 1 \mathrm{H}, \mathrm{H}-11, J_{\mathrm{gem}}=18.0, J_{11,12}=9.9, J_{11,12}=1.2 \mathrm{~Hz}\right), 2.41\left(\mathrm{dd}, 1 \mathrm{H}, \mathrm{H}-11, J_{\mathrm{gem}}=18.9, J_{11,12}=9.2\right.$ Hz), 2.20-2.13 (m, 1H, H-12), 2.11-2.05 (m, 1H, H-12), 1.86-1.82 (m, 2H, H-12), 1.40 (d, 3H, H-6", J J",5" = 6.3 Hz), $1.36\left(\mathrm{~d}, 3 \mathrm{H}, \mathrm{H}-6, J_{6,5}=6.3 \mathrm{~Hz}\right), 1.33$ (d, 3H, H-6, $\left.J_{6,5}=5.7 \mathrm{~Hz}\right), 1.22$ (d, 3H, H-14, $\left.J_{14,13}=5.7 \mathrm{~Hz}\right), 1.22(\mathrm{~d}, 3 \mathrm{H}, \mathrm{H}-$ $\left.14, J_{14,13}=6.3 \mathrm{~Hz}\right) ;{ }^{13} \mathrm{C}$ NMR $\left(100 \mathrm{MHz}\right.$, acetone- $\left.d_{6}\right) \delta 206.3,206.0,205.8,174.3,173.2,171.8,165.6,165.5,149.3$, 149.0, 121.7, 121.2, 76.7, 76.2, 73.3, 73.0, 72.1, 71.9, 71.8, 57.1, 46.4, 46.3, 43.7, 41.3, 40.4, 39.3, 39.1, 29.1, 28.4, 21.9, 20.3, 20.1, 18.4, 18.3; LRMS (ESI) $m / z:[\mathrm{M}+\mathrm{Na}]^{+}$715.3; HRMS (ESI) $m / z:[\mathrm{M}+\mathrm{Na}]^{+}$calcd for $\mathrm{C}_{34} \mathrm{H}_{44} \mathrm{O}_{15} \mathrm{Na}$ 715.2573 , found $715.2571 ;[\alpha]^{21} \mathrm{D}=+98.26(c 0.29, \mathrm{MeOH})$.

\section{(+)-Acaulone A (2)}

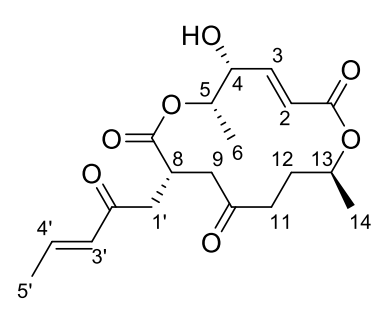

To a solution of $\mathbf{1 9}(10.0 \mathrm{mg}, 21.9 \mu \mathrm{mol})$ in 1,2-dichloroethane $(950 \mu \mathrm{L})$ were added $0.1 \mathrm{M}$ phosphate buffer ( $\mathrm{pH} 7.0)(50 \mu \mathrm{L})$ and DDQ $(24.9 \mathrm{mg}, 109 \mu \mathrm{mol}, 5.0$ equiv.). The reaction mixture was heated to $80^{\circ} \mathrm{C}$ and stirred for $4 \mathrm{~h}$. Upon completion of the reaction, the mixture was cooled to $0{ }^{\circ} \mathrm{C}$ and poured into sat. aq. $\mathrm{NaHCO}_{3}$. The aqueous phase was extracted with $\mathrm{CH}_{2} \mathrm{Cl}_{2}$. The combined organic phase was washed with brine, dried over $\mathrm{Na}_{2} \mathrm{SO}_{4}$, filtered and concentrated in vacuo. The residue was purified by flash silica gel column chromatography $(\phi 1.3 \times 13 \mathrm{~cm}$, AcOEt/hexane $=45-50 \%)$ to afford $2(4.1 \mathrm{mg}, 11.2 \mu \mathrm{mol}, 51 \%)$ as a white 
foam.

${ }^{1} \mathrm{H}$ NMR $\left(400 \mathrm{MHz}, \mathrm{CDCl}_{3}\right) \delta 6.87\left(\mathrm{dq}, 1 \mathrm{H}, \mathrm{H}-4^{\prime}, J_{4^{\prime}, 3^{\prime}}=15.9, J_{4^{\prime}, 5^{\prime}}=6.8 \mathrm{~Hz}\right), 6.77\left(\mathrm{dd}, 1 \mathrm{H}, \mathrm{H}-3, J_{3,2}=15.9, J_{3,4}=\right.$ $3.6 \mathrm{~Hz}), 6.09$ (dq, $\left.1 \mathrm{H}, \mathrm{H}-3^{\prime}, J_{3^{\prime}, 4^{\prime}}=15.9, J_{3^{\prime}, 5^{\prime}}=1.8 \mathrm{~Hz}\right), 5.99\left(\mathrm{dd}, 1 \mathrm{H}, \mathrm{H}-2, J_{2,3}=15.9, J_{2,4}=1.8 \mathrm{~Hz}\right), 4.98(\mathrm{dqd}, 1 \mathrm{H}$, $\mathrm{H}-13, J_{13,12}=7.3, J_{13,14}=6.3, J_{13,12}=4.3 \mathrm{~Hz}$ ), 4.68 (quin, $1 \mathrm{H}, \mathrm{H}-5, J_{5,4}=J_{5,6}=6.3 \mathrm{~Hz}$ ), $4.21\left(\mathrm{dddd}, 1 \mathrm{H}, \mathrm{H}-4, J_{4, \mathrm{OH}}=\right.$ $\left.8.3, J_{4,5}=6.3, J_{4,3}=3.6, J_{4,2}=1.8 \mathrm{~Hz}\right), 3.41-3.35(\mathrm{~m}, 1 \mathrm{H}, \mathrm{H}-8), 3.13\left(\mathrm{dd}, 1 \mathrm{H}, \mathrm{H}-1^{\prime}, J_{\mathrm{gem}}=17.7, J_{1^{\prime}, 8}=7.7 \mathrm{~Hz}\right), 2.78-$ 2.75 (m, 3H, H-9, OH), 2.55 (ddd, $\left.1 \mathrm{H}, \mathrm{H}-11, J_{\mathrm{gem}}=17.9, J_{11,12}=8.8, J_{11,12}=1.4 \mathrm{~Hz}\right), 2.53\left(\mathrm{dd}, 1 \mathrm{H}, \mathrm{H}-1^{\prime}, J_{\mathrm{gem}}=17.7\right.$, $J_{1^{\prime}, 8}=6.3 \mathrm{~Hz}$ ), $2.29\left(\mathrm{ddd}, 1 \mathrm{H}, \mathrm{H}-11, J_{\text {gem }}=17.9, J_{11,12}=9.3, J_{11,12}=1.7 \mathrm{~Hz}\right), 2.04$ (dddd, $1 \mathrm{H}, \mathrm{H}-12, J_{\text {gem }}=19.1, J_{12,11}$ $\left.=8.8, J_{12,13}=4.3, J_{12,11}=1.8 \mathrm{~Hz}\right), 1.98-1.94(\mathrm{~m}, 1 \mathrm{H}, \mathrm{H}-12), 1.90\left(\mathrm{dd}, 3 \mathrm{H}, \mathrm{H}-5^{\prime}, J_{5^{\prime}, 4^{\prime}}=6.8, J_{5^{\prime}, 3^{\prime}}=1.8 \mathrm{~Hz}\right), 1.45(\mathrm{~d}, 3 \mathrm{H}$, $\left.\mathrm{H}-6, J_{6,5}=6.3 \mathrm{~Hz}\right), 1.27$ (d, 3H, H-14, $\left.J_{14,13}=6.3 \mathrm{~Hz}\right) ;{ }^{13} \mathrm{C} \mathrm{NMR}\left(100 \mathrm{MHz}, \mathrm{CDCl}_{3}\right) \delta 205.6,197.6,174.5,165.1$, $146.3,143.7,131.5,121.7,75.9,73.8,70.5,44.4,40.5,37.9,34.6,27.6,19.6,18.4,18.3 ;$ LRMS (ESI) $m / z:[\mathrm{M}+\mathrm{Na}]^{+}$ 389.3; HRMS (ESI) $m / z$ : $[\mathrm{M}+\mathrm{Na}]^{+}$calcd for $\mathrm{C}_{19} \mathrm{H}_{26} \mathrm{O}_{7} \mathrm{Na} 389.1571$, found 389.1562; $[\alpha]^{19}{ }_{\mathrm{D}}=+44.08(c 0.21, \mathrm{MeOH})$. 


\section{Examination of Michael addition}

Table S1. Examination of the stepwise Michael addition

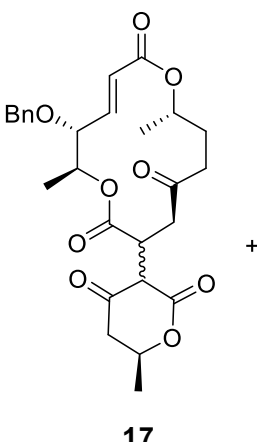

1.0 equiv. (crude)

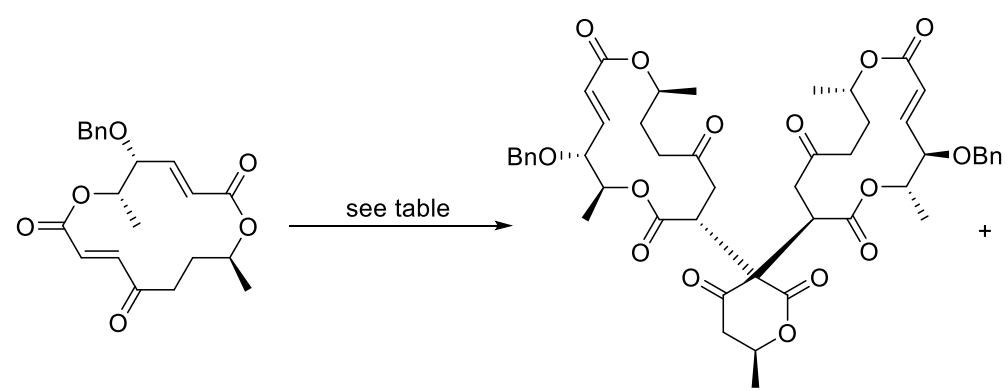

18

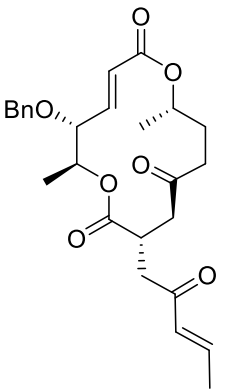

19

\begin{tabular}{|c|c|c|c|c|c|c|c|c|}
\hline \multirow{2}{*}{ entry } & \multirow{2}{*}{$\begin{array}{c}\text { base } \\
(1.5 \text { equiv.) }\end{array}$} & \multirow{2}{*}{ solvent } & \multirow{2}{*}{$\begin{array}{c}\text { additive } \\
(0.5 \text { equiv. })\end{array}$} & \multirow{2}{*}{ temp. $\left({ }^{\circ} \mathrm{C}\right)$} & \multirow{2}{*}{ time $(\mathrm{h})$} & \multicolumn{2}{|c|}{ yield (\%) (2 steps) } & \multirow{2}{*}{$\frac{\text { SM rec. }(\%)}{7}$} \\
\hline & & & & & & 18 & 19 & \\
\hline 1 & $\mathrm{Cs}_{2} \mathrm{CO}_{3}$ & $\mathrm{MeCN}$ & - & 25 & 20 & 0 & 0 & 60 \\
\hline 2 & $\mathrm{Et}_{3} \mathrm{~N}$ & $\mathrm{MeCN}$ & - & 25 & 20 & 18 & 21 & 28 \\
\hline 3 & pyridine & $\mathrm{MeCN}$ & - & 25 & 20 & 13 & 8 & 78 \\
\hline 4 & DBU & $\mathrm{MeCN}$ & - & 25 & 20 & 0 & 11 & 0 \\
\hline 5 & DABCO & $\mathrm{MeCN}$ & - & 25 & 20 & 24 & 26 & 36 \\
\hline 6 & NMM & $\mathrm{MeCN}$ & - & 25 & 20 & 40 & 18 & 36 \\
\hline 7 & NMI & $\mathrm{MeCN}$ & - & 25 & 20 & 34 & 13 & 2 \\
\hline 8 & lutidine & $\mathrm{MeCN}$ & - & 25 & 20 & 19 & 8 & 46 \\
\hline 9 & NMM & DMF & - & 25 & 20 & 29 & 23 & 52 \\
\hline 10 & NMM & DCE & - & 25 & 20 & 42 & 10 & 34 \\
\hline 11 & NMM & toluene & - & 25 & 20 & 38 & 18 & 56 \\
\hline 12 & NMM & pyridine & - & 25 & 20 & 24 & 8 & 68 \\
\hline 13 & NMM & pyridine & $\mathrm{AcOH}$ & 25 & 20 & 28 & 18 & 22 \\
\hline 14 & NMM & $\mathrm{MeCN}$ & $\mathrm{AcOH}$ & 25 & 20 & 37 & 20 & 20 \\
\hline 15 & NMM & toluene & $\mathrm{AcOH}$ & 25 & 20 & 34 & 15 & 38 \\
\hline 16 & NMM & DCE & $\mathrm{AcOH}$ & 25 & 20 & 39 & 15 & 30 \\
\hline 17 & NMM & DCE & - & 40 & 20 & 35 & 36 & 18 \\
\hline 18 & NMM & DCE & $\mathrm{AcOH}$ & 40 & 20 & 44 & 36 & 18 \\
\hline 19 & NMM & DCE & - & 25 & 66 & 53 & 7 & 30 \\
\hline
\end{tabular}


Table S2. Examination of the one-pot Michael addition
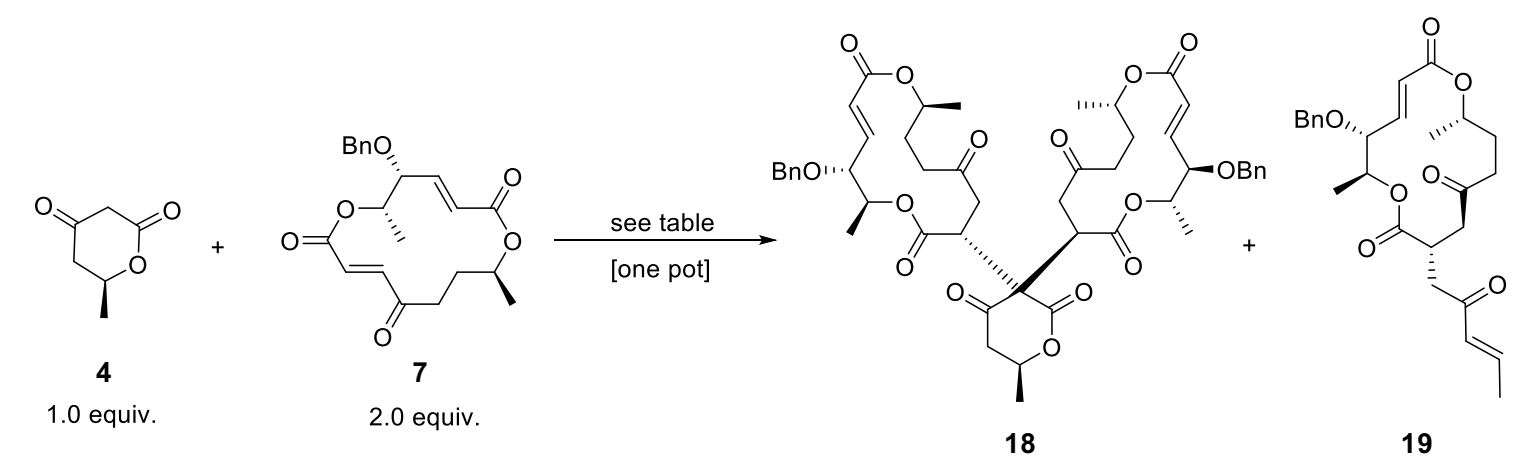

19

\begin{tabular}{|c|c|c|c|c|c|c|c|}
\hline \multirow{2}{*}{ entry } & \multirow{2}{*}{$\begin{array}{c}\text { base } \\
\text { (2.5 equiv.) }\end{array}$} & \multirow{2}{*}{ additive } & \multirow{2}{*}{ solvent } & \multirow{2}{*}{ temp. $\left({ }^{\circ} \mathrm{C}\right)$} & \multirow{2}{*}{ time $(\mathrm{h})$} & \multicolumn{2}{|c|}{ yield $(\%)$} \\
\hline & & & & & & 18 & 19 \\
\hline 1 & NMM & - & DCE & 25 & 66 & 27 & 44 \\
\hline 2 & NMM & - & DCE & r.t. to 40 & 10 & 32 & 25 \\
\hline 3 & NMM & $\mathrm{AcOH}(0.5$ eq. $)$ & DCE & r.t. to 40 & 10 & 36 & 21 \\
\hline 4 & DABCO & - & DCE & r.t. to 40 & 10 & 23 & 56 \\
\hline 5 & DABCO & - & pyridine & r.t. to 40 & 10 & 27 & 41 \\
\hline 6 & DABCO & $\mathrm{AcOH}$ & pyridine & r.t. to 40 & 10 & 45 & 30 \\
\hline 7 & DABCO & $\mathrm{AcOH}$ & pyridine & r.t. to 40 & 20 & 9 & 62 \\
\hline 8 & $\mathrm{Et}_{3} \mathrm{~N}$ & $\mathrm{AcOH}$ & pyridine & r.t. to 40 & 10 & 41 & 34 \\
\hline 9 & DABCO & $\mathrm{AcOH}$ (3.5 eq.) & pyridine & r.t. to 40 & 9 & 26 & 25 \\
\hline 10 & DABCO & $\mathrm{Et}_{3} \mathrm{~N} \cdot \mathrm{HCl}$ (2.5 eq.) & pyridine & r.t. to 40 & 9 & 10 & 24 \\
\hline 11 & - & $\mathrm{Et}_{3} \mathrm{~N} \cdot \mathrm{HCl}$ (2.5 eq.) & pyridine & r.t. to 40 & 9 & 16 & 11 \\
\hline 12 & DABCO & $\mathrm{AcOH}(0.5$ eq.) & pyr./'PrOH (9/1) & r.t. to 40 & 7 & 4 & 20 \\
\hline 13 & DABCO & $\mathrm{AcOH}(0.5$ eq. $)$ & pyr./HFIP (9/1) & r.t. to 40 & 7 & 16 & 48 \\
\hline 14 & DABCO & $\mathrm{AcOH}(0.5$ eq. $)$ & pyr./'PrOH (4/1) & r.t. to 40 & 9 & 6 & 37 \\
\hline 15 & DABCO & $\mathrm{AcOH}(0.5$ eq. $)$ & pyr./HFIP (4/1) & r.t. to 40 & 9 & 29 & 42 \\
\hline 16 & DABCO & $\mathrm{AcOH}(0.5$ eq. $)$ & pyr./TFE (4/1) & r.t. to 40 & 9 & 16 & 37 \\
\hline
\end{tabular}




\section{HPLC analysis for determining the enantiopurity of 14}

Table S3. Determination of enantiopurity of 14

Condition: CHIRALPAK-IC (DAISEL: $\phi 4.6 \mathrm{~mm} \times \mathrm{L}$ 150mm), $10 \% i$-PrOH/hexane, $1.0 \mathrm{~mL} / \mathrm{min}, 210 \mathrm{~nm}$

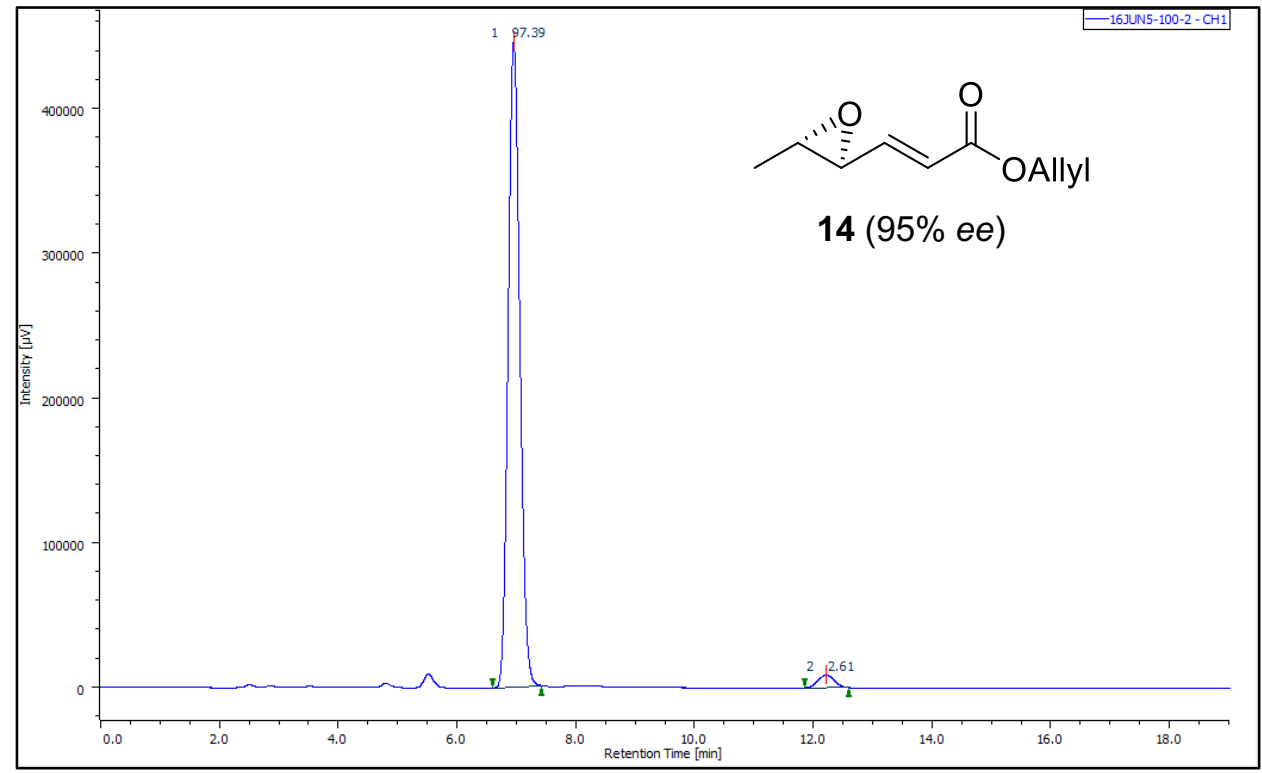

\begin{tabular}{ccccc}
\hline peak & $\mathrm{t}_{\mathrm{R}}(\mathrm{min})$ & area $\left(\mathrm{mAU}^{*} \mathrm{~s}\right)$ & height $(\mathrm{mAU})$ & area(\%) \\
\hline 1 & 6.95 & 6081292 & 445499 & 97.39 \\
2 & 12.21 & 8640 & 8640 & 2.61
\end{tabular}

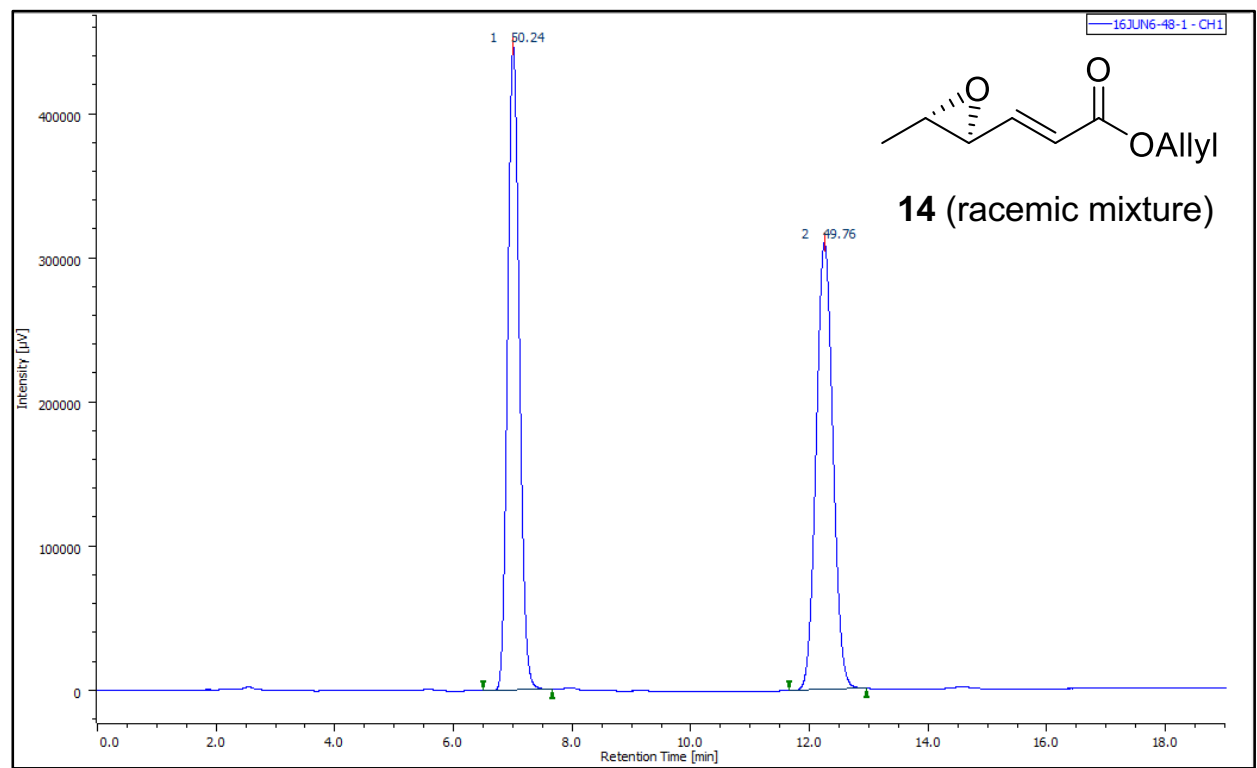

\begin{tabular}{ccccc}
\hline peak & $\mathrm{t}_{\mathrm{R}}(\mathrm{min})$ & area $\left(\mathrm{mAU}^{*} \mathrm{~s}\right)$ & height $(\mathrm{mAU})$ & area(\%) \\
\hline 1 & 7.00 & 6139564 & 446039 & 50.24 \\
2 & 12.24 & 6080610 & 309617 & 49.76
\end{tabular}




\section{X-Ray crystallographic data of 7}

Figure S1. Full ORTEP plot of 7

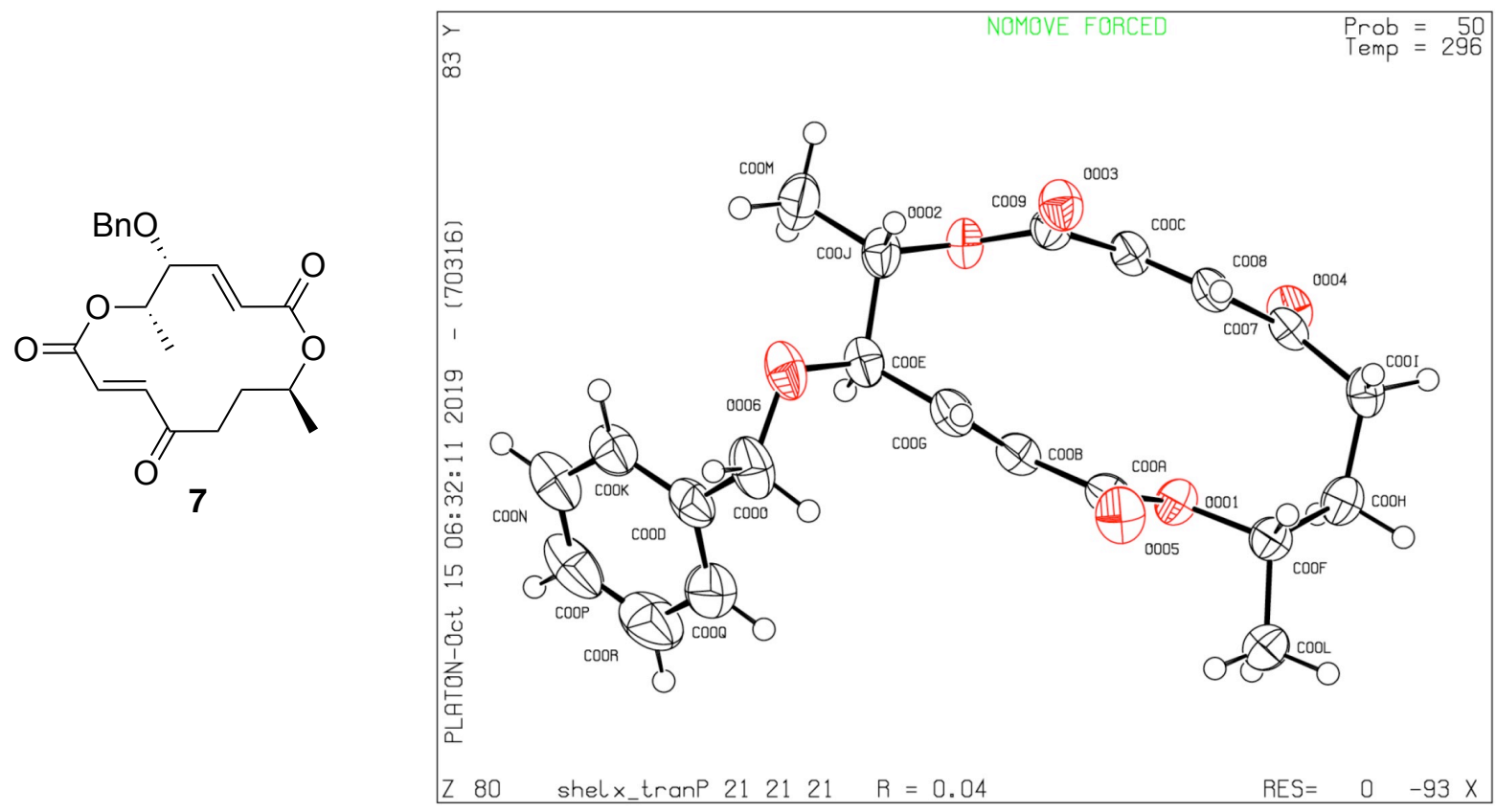

The colorless crystal of 7 was obtained by recrystallization from $\mathrm{CHCl}_{3} /$ hexane. The data were collected on Rigaku R-AXIS RAPID II. The ellipsoids were drawn at the 50\% probability level. The crystallographic data were deposited in the Cambridge Crystallographic Data Center, CCDC 2008466. 
Table S4. Crystal data and structure refinement for 7

Identification code

Empirical formula

Formula weight

Temperature

Wavelength

Crystal system

Space group

Unit cell dimensions

Volume

Z

Density (calculated)

Absorption coefficient

$\mathrm{F}(000)$

Crystal size

Theta range for data collection

Index ranges

Reflections collected

Independent reflections

Completeness to theta $=67.680^{\circ}$

Absorption correction

Max. and min. transmission

Refinement method

Data / restraints / parameters

Goodness-of-fit on $\mathrm{F}^{2}$

Final $\mathrm{R}$ indices [I $>2 \operatorname{sigma}(\mathrm{I})]$

$\mathrm{R}$ indices (all data)

Absolute structure parameter

Extinction coefficient

Largest diff. peak and hole shelx_trans

C21 H24 O6

372.40

296(2) K

$1.5418 \AA$

Orthorhombic

$\mathrm{P} 2{ }_{12}{ }_{1}$

$a=5.12200(10) \AA$

$\mathrm{a}=90^{\circ}$.

$\mathrm{b}=14.9326(3) \AA$

$\mathrm{b}=90^{\circ}$.

$\mathrm{c}=25.5046(5) \AA$

$\mathrm{g}=90^{\circ}$.

1950.71(7) $\AA^{3}$

4

$1.268 \mathrm{Mg} / \mathrm{m}^{3}$

$0.764 \mathrm{~mm}^{-1}$

792

$0.740 \times 0.110 \times 0.100 \mathrm{~mm}^{3}$

3.430 to $68.220^{\circ}$.

$-5<=\mathrm{h}<=5,-17<=\mathrm{k}<=17,-29<=\mathrm{l}<=30$

22572

$3507[\mathrm{R}($ int $)=0.0540]$

$98.7 \%$

Semi-empirical from equivalents

1.0000 and 0.7460

Full-matrix least-squares on $\mathrm{F}^{2}$

3507 / 0 / 246

1.083

$\mathrm{R} 1=0.0421, \mathrm{wR} 2=0.0997$

$\mathrm{R} 1=0.0462, \mathrm{wR} 2=0.1023$

$0.04(8)$

$\mathrm{n} / \mathrm{a}$

0.163 and -0.160 e. $\AA^{-3}$ 
Table S5. Bond lengths $[\AA]$ and angles $\left[{ }^{\circ}\right]$ for 7

$\begin{array}{lr}\mathrm{O}(001)-\mathrm{C}(00 \mathrm{~A}) & 1.339(3) \\ \mathrm{O}(001)-\mathrm{C}(00 \mathrm{~F}) & 1.461(3) \\ \mathrm{O}(002)-\mathrm{C}(009) & 1.350(3) \\ \mathrm{O}(002)-\mathrm{C}(00 \mathrm{~J}) & 1.453(3) \\ \mathrm{O}(003)-\mathrm{C}(009) & 1.204(3) \\ \mathrm{O}(004)-\mathrm{C}(007) & 1.221(3) \\ \mathrm{O}(005)-\mathrm{C}(00 \mathrm{~A}) & 1.202(3) \\ \mathrm{O}(006)-\mathrm{C}(00 \mathrm{E}) & 1.428(3) \\ \mathrm{O}(006)-\mathrm{C}(00 \mathrm{O}) & 1.433(4) \\ \mathrm{C}(007)-\mathrm{C}(008) & 1.485(3) \\ \mathrm{C}(007)-\mathrm{C}(00 \mathrm{I}) & 1.511(3) \\ \mathrm{C}(008)-\mathrm{C}(00 \mathrm{C}) & 1.325(3) \\ \mathrm{C}(009)-\mathrm{C}(00 \mathrm{C}) & 1.482(4) \\ \mathrm{C}(00 \mathrm{~A})-\mathrm{C}(00 \mathrm{~B}) & 1.482(3) \\ \mathrm{C}(00 \mathrm{~B})-\mathrm{C}(00 \mathrm{G}) & 1.323(4) \\ \mathrm{C}(00 \mathrm{D})-\mathrm{C}(00 \mathrm{~K}) & 1.380(4) \\ \mathrm{C}(00 \mathrm{D})-\mathrm{C}(00 \mathrm{O}) & 1.496(4) \\ \mathrm{C}(00 \mathrm{D})-\mathrm{C}(00 \mathrm{Q}) & 1.396(5) \\ \mathrm{C}(00 \mathrm{E})-\mathrm{C}(00 \mathrm{G}) & 1.497(4) \\ \mathrm{C}(00 \mathrm{E})-\mathrm{C}(00 \mathrm{~J}) & 1.538(4) \\ \mathrm{C}(00 \mathrm{~F})-\mathrm{C}(00 \mathrm{H}) & 1.508(4) \\ \mathrm{C}(00 \mathrm{~F})-\mathrm{C}(00 \mathrm{~L}) & 1.503(4) \\ \mathrm{C}(00 \mathrm{H})-\mathrm{C}(00 \mathrm{I}) & 1.541(4) \\ \mathrm{C}(00 \mathrm{~J})-\mathrm{C}(00 \mathrm{M}) & 1.511(4) \\ \mathrm{C}(00 \mathrm{~K})-\mathrm{C}(00 \mathrm{~N}) & 1.377(4) \\ \mathrm{C}(00 \mathrm{~N})-\mathrm{C}(00 \mathrm{P}) & 1.359(5) \\ \mathrm{C}(00 \mathrm{P})-\mathrm{C}(00 \mathrm{R}) & 1.377(6) \\ \mathrm{C}(00 \mathrm{Q})-\mathrm{C}(00 \mathrm{R}) & 1.394(5) \\ \mathrm{C}(00 \mathrm{~A})-\mathrm{O}(001)-\mathrm{C}(00 \mathrm{~F}) & \\ \mathrm{C}(009)-\mathrm{O}(002)-\mathrm{C}(00 \mathrm{~J}) & 117.6(2) \\ \mathrm{C}(00 \mathrm{E})-\mathrm{O}(006)-\mathrm{C}(00 \mathrm{O}) & \\ \mathrm{O}(004)-\mathrm{C}(007)-\mathrm{C}(008) & \\ \mathrm{O}(004)-\mathrm{C}(007)-\mathrm{C}(00 \mathrm{I}) & \\ & 120.7(3) \\ & \end{array}$

$\begin{array}{ll}\mathrm{C}(008)-\mathrm{C}(007)-\mathrm{C}(00 \mathrm{I}) & 118.4(2) \\ \mathrm{C}(00 \mathrm{C})-\mathrm{C}(008)-\mathrm{C}(007) & 122.4(2) \\ \mathrm{O}(002)-\mathrm{C}(009)-\mathrm{C}(00 \mathrm{C}) & 109.7(2) \\ \mathrm{O}(003)-\mathrm{C}(009)-\mathrm{O}(002) & 124.8(3) \\ \mathrm{O}(003)-\mathrm{C}(009)-\mathrm{C}(00 \mathrm{C}) & 125.4(2) \\ \mathrm{O}(001)-\mathrm{C}(00 \mathrm{~A})-\mathrm{C}(00 \mathrm{~B}) & 110.1(2) \\ \mathrm{O}(005)-\mathrm{C}(00 \mathrm{~A})-\mathrm{O}(001) & 124.6(3) \\ \mathrm{O}(005)-\mathrm{C}(00 \mathrm{~A})-\mathrm{C}(00 \mathrm{~B}) & 125.3(3) \\ \mathrm{C}(00 \mathrm{G})-\mathrm{C}(00 \mathrm{~B})-\mathrm{C}(00 \mathrm{~A}) & 121.4(3) \\ \mathrm{C}(008)-\mathrm{C}(00 \mathrm{C})-\mathrm{C}(009) & 119.1(2) \\ \mathrm{C}(00 \mathrm{~K})-\mathrm{C}(00 \mathrm{D})-\mathrm{C}(00 \mathrm{O}) & 120.1(3) \\ \mathrm{C}(00 \mathrm{~K})-\mathrm{C}(00 \mathrm{D})-\mathrm{C}(00 \mathrm{Q}) & 117.9(3) \\ \mathrm{C}(00 \mathrm{Q})-\mathrm{C}(00 \mathrm{D})-\mathrm{C}(00 \mathrm{O}) & 122.0(3) \\ \mathrm{O}(006)-\mathrm{C}(00 \mathrm{E})-\mathrm{C}(00 \mathrm{G}) & 111.2(2) \\ \mathrm{O}(006)-\mathrm{C}(00 \mathrm{E})-\mathrm{C}(00 \mathrm{~J}) & 105.3(2) \\ \mathrm{C}(00 \mathrm{G})-\mathrm{C}(00 \mathrm{E})-\mathrm{C}(00 \mathrm{~J}) & 111.8(2) \\ \mathrm{O}(001)-\mathrm{C}(00 \mathrm{~F})-\mathrm{C}(00 \mathrm{H}) & 106.7(2) \\ \mathrm{O}(001)-\mathrm{C}(00 \mathrm{~F})-\mathrm{C}(00 \mathrm{~L}) & 108.3(2) \\ \mathrm{C}(00 \mathrm{~L})-\mathrm{C}(00 \mathrm{~F})-\mathrm{C}(00 \mathrm{H}) & 112.6(3) \\ \mathrm{C}(00 \mathrm{~B})-\mathrm{C}(00 \mathrm{G})-\mathrm{C}(00 \mathrm{E}) & 124.7(3) \\ \mathrm{C}(00 \mathrm{~F})-\mathrm{C}(00 \mathrm{H})-\mathrm{C}(00 \mathrm{I}) & 115.9(2) \\ \mathrm{C}(007)-\mathrm{C}(00 \mathrm{I})-\mathrm{C}(00 \mathrm{H}) & 113.2(2) \\ \mathrm{O}(002)-\mathrm{C}(00 \mathrm{~J})-\mathrm{C}(00 \mathrm{E}) & 105.9(2) \\ \mathrm{O}(002)-\mathrm{C}(00 \mathrm{~J})-\mathrm{C}(00 \mathrm{M}) & 107.0(2) \\ \mathrm{C}(00 \mathrm{M})-\mathrm{C}(00 \mathrm{~J})-\mathrm{C}(00 \mathrm{E}) & 113.2(2) \\ \mathrm{C}(00 \mathrm{~N})-\mathrm{C}(00 \mathrm{~K})-\mathrm{C}(00 \mathrm{D}) & 121.6(3) \\ \mathrm{C}(00 \mathrm{P})-\mathrm{C}(00 \mathrm{~N})-\mathrm{C}(00 \mathrm{~K}) & 120.9(4) \\ \mathrm{O}(006)-\mathrm{C}(00 \mathrm{O})-\mathrm{C}(00 \mathrm{D}) & 113.3(3) \\ \mathrm{C}(00 \mathrm{~N})-\mathrm{C}(00 \mathrm{P})-\mathrm{C}(00 \mathrm{R}) & 118.8(4) \\ \mathrm{C}(00 \mathrm{R})-\mathrm{C}(00 \mathrm{Q})-\mathrm{C}(00 \mathrm{D})-\mathrm{C}(00 \mathrm{R})-\mathrm{C}(00 \mathrm{Q}) & 119.6(4) \\ & 121.2(4)\end{array}$

Symmetry transformations used to generate equivalent atoms: 


\section{Comparison of the NMR data of isolated and synthetic acaulide (1)}

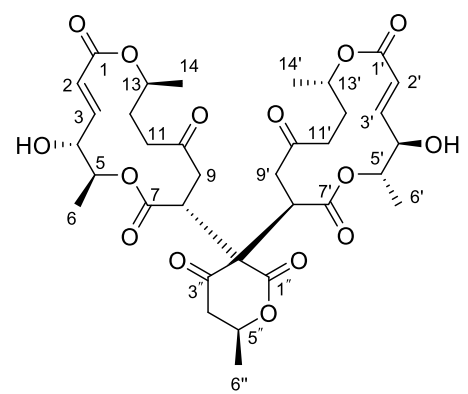

isolated $\left(600 \mathrm{MHz} \text {, acetone- } d_{6}\right)^{1)}$

synthetic (500 MHz, acetone- $d_{6}$ )

\begin{tabular}{|c|c|c|c|c|}
\hline position & ${ }^{1} \mathrm{H} \delta$ (mult, $J$ in $\mathrm{Hz}$ ) & ${ }^{13} \mathrm{C} \delta$ & ${ }^{1} \mathrm{H} \delta$ (mult, $J$ in $\mathrm{Hz}$ ) & ${ }^{13} \mathrm{C} \delta$ \\
\hline 1 & & 165.5 & & 165.5 \\
\hline 2 & $5.82(\mathrm{dd}, 15.81 .7)$ & 121.1 & $5.82(\mathrm{dd}, 16.01 .7)$ & 121.2 \\
\hline 3 & $6.71(\mathrm{dd}, 15.84 .3)$ & 149.3 & $6.70(\mathrm{dd}, 16.04 .6)$ & 149.3 \\
\hline 4 & 4.16 (ddd, 9.24 .31 .7$)$ & 72.8 & 4.15 (ddd, 9.54 .61 .7$)$ & 73.0 \\
\hline 5 & $4.47(\mathrm{dq}, 9.26 .2)$ & 76.1 & $4.47(\mathrm{dq}, 9.56 .3)$ & 76.2 \\
\hline 6 & $1.37(\mathrm{~d}, 6.2)$ & 18.3 & $1.36(\mathrm{~d}, 6.3)$ & 18.3 \\
\hline 7 & & 173.1 & & 173.2 \\
\hline 8 & $3.62(\mathrm{dd}, 6.73 .4)$ & 46.3 & $3.62(\mathrm{dd}, 6.63 .6)$ & 46.3 \\
\hline $9 \mathrm{a}$ & $2.73(\mathrm{dd}, 19.16 .7)$ & 40.3 & $2.72(\mathrm{dd}, 19.16 .9)$ & 40.4 \\
\hline $9 b$ & $3.01(\mathrm{dd}, 19.13 .4)$ & & $3.01(\mathrm{dd}, 19.13 .4)$ & \\
\hline 10 & & 206.1 & & 206.0 \\
\hline $11 \mathrm{a}$ & $2.42(\mathrm{dd}, 18.49 .5)$ & 39.3 & $2.41(\mathrm{dd}, 18.99 .2)$ & 39.3 \\
\hline $11 \mathrm{~b}$ & $2.70(\mathrm{dd}, 18.48 .6)$ & & $2.70(\mathrm{dd}, 18.98 .6)$ & \\
\hline $12 \mathrm{a}$ & $1.85 \mathrm{~m}$ & 28.4 & $1.86-1.82 \mathrm{~m}$ & 28.4 \\
\hline $12 b$ & $2.08 \mathrm{~m}$ & & $2.12-2.06 \mathrm{~m}$ & \\
\hline 13 & $4.78 \mathrm{~m}$ & 71.8 & $4.80-4.75 \mathrm{~m}$ & 71.8 \\
\hline 14 & $1.23(\mathrm{~d}, 6.2)$ & 20.1 & $1.23(\mathrm{~d}, 5.7)$ & 20.1 \\
\hline $1^{\prime}$ & & 165.6 & & 165.6 \\
\hline $2^{\prime}$ & $5.85(\mathrm{dd}, 15.81 .6)$ & 121.6 & $5.84(\mathrm{dd}, 15.51 .7)$ & 121.7 \\
\hline $3^{\prime}$ & $6.77(\mathrm{dd}, 15.84 .6)$ & 149.0 & $6.77(\mathrm{dd}, 15.54 .6)$ & 149.0 \\
\hline $4^{\prime}$ & 4.19 (ddd, 8.94 .6 1.6) & 73.2 & 4.19 (ddd, 9.34 .6 1.7) & 73.3 \\
\hline $5^{\prime}$ & $4.30(\mathrm{dq}, 8.96 .1)$ & 76.6 & $4.30(\mathrm{dq}, 9.36 .0)$ & 76.7 \\
\hline $6^{\prime}$ & $1.33(\mathrm{~d}, 6.1)$ & 18.4 & $1.33(\mathrm{~d}, 5.7)$ & 18.4 \\
\hline $7^{\prime}$ & & 174.3 & & 174.3 \\
\hline $8^{\prime}$ & $3.97(\mathrm{t}, 4.6)$ & 43.7 & $3.97(\mathrm{t}, 4.6)$ & 43.7 \\
\hline $9^{\prime} \mathrm{a}$ & $2.72(\mathrm{dd}, 19.94 .6)$ & 41.3 & $2.70(\mathrm{dd}, 19.94 .6)$ & 41.3 \\
\hline $9^{\prime} b$ & $3.50(\mathrm{dd}, 19.94 .6)$ & & $3.50(\mathrm{dd}, 19.94 .6)$ & \\
\hline $10^{\prime}$ & & 205.8 & & 205.8 \\
\hline $11^{\prime} \mathrm{a}$ & $2.53(\mathrm{dd}, 18.09 .8)$ & 39.1 & $2.52(\mathrm{ddd}, 18.09 .9,1.2)$ & 39.1 \\
\hline $11^{\prime} \mathrm{b}$ & $2.62(\mathrm{dd}, 18.58 .9$ & & $2.62(\mathrm{ddd}, 18.09 .21 .7)$ & \\
\hline $12^{\prime} \mathrm{a}$ & $1.85 \mathrm{~m}$ & 29.0 & $1.86-1.82 \mathrm{~m}$ & 29.1 \\
\hline $12^{\prime} \mathrm{b}$ & $2.16 \mathrm{~m}$ & & $2.20-2.13 \mathrm{~m}$ & \\
\hline $13^{\prime}$ & $4.83 \mathrm{~m}$ & 72.1 & $4.83(\mathrm{dqd}, 9.7,6.3,3.3)$ & 72.1 \\
\hline $14^{\prime}$ & $1.24(\mathrm{~d}, 6.2)$ & 20.3 & $1.22(\mathrm{~d}, 6.3)$ & 20.3 \\
\hline $1^{\prime \prime}$ & & 171.9 & & 171.9 \\
\hline $2^{\prime \prime}$ & & 57.1 & & 57.1 \\
\hline $3^{\prime \prime}$ & & 206.4 & & 206.5 \\
\hline $4^{\prime \prime} \mathrm{a}$ & $2.58(\mathrm{dd}, 15.72 .8)$ & 46.4 & $2.58(\mathrm{dd}, 15.82 .9)$ & 46.4 \\
\hline $4^{\prime \prime} \mathrm{a}$ & $3.05(\mathrm{dd}, 15.712 .5)$ & & $3.05(\mathrm{dd}, 15.812 .6)$ & \\
\hline $5^{\prime \prime}$ & $4.79 \mathrm{~m}$ & 71.9 & $4.80-4.75 \mathrm{~m}$ & 71.9 \\
\hline $6^{\prime \prime}$ & $1.41(\mathrm{~d}, 6.2)$ & 21.9 & $1.40(\mathrm{~d}, 6.3)$ & 21.9 \\
\hline
\end{tabular}




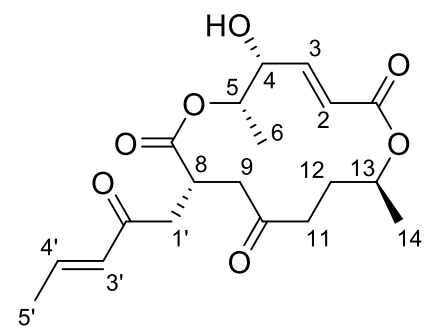

\begin{tabular}{ccccc} 
& \multicolumn{2}{c}{ isolated $\left(400 \mathrm{MHz}, \mathrm{CDCl}_{3}\right)^{1)}$} & \multicolumn{2}{c}{ synthetic $\left(400 \mathrm{MHz}, \mathrm{CDCl}_{3}\right)$} \\
\hline position & ${ }^{1} \mathrm{H} \delta($ mult, $J$ in $\mathrm{Hz})$ & ${ }^{13} \mathrm{C} \delta$ & ${ }^{1} \mathrm{H} \delta(\mathrm{mult}, J$ in $\mathrm{Hz})$ & ${ }^{13} \mathrm{C} \delta$ \\
\hline 1 & & 165.1 & & 165.1 \\
2 & $5.99(\mathrm{dd}, 15.81 .9)$ & 121.7 & $5.99(\mathrm{dd}, 15.81 .9)$ & 121.7 \\
3 & $6.77(\mathrm{dd}, 15.83 .8)$ & 146.4 & $6.77(\mathrm{dd}, 15.83 .6)$ & 146.3 \\
4 & $4.21 \mathrm{~m}$ & 73.8 & $4.21(\mathrm{dddd}, 8.36 .33 .61 .9)$ & 73.8 \\
5 & $4.68($ quin, 6.4$)$ & 75.9 & $4.68(\mathrm{quin}, 6.3)$ & 75.9 \\
6 & $1.44(\mathrm{~d}, 6.4)$ & 18.2 & $1.45(\mathrm{~d}, 6.3)$ & 18.3 \\
7 & & 174.8 & & 174.8 \\
8 & $3.38 \mathrm{~m}$ & 34.6 & $3.41-3.35 \mathrm{~m}$ & 34.6 \\
9 & $2.76 \mathrm{~m}$ & 44.4 & $2.78-2.75 \mathrm{~m}$ & 44.4 \\
10 & & 205.6 & & 205.6 \\
$11 \mathrm{a}$ & $2.29(\mathrm{ddd}, 17.99 .31 .5)$ & 37.9 & $2.29(\mathrm{ddd}, 17.99 .31 .7)$ & 37.9 \\
$11 \mathrm{~b}$ & $2.54(\mathrm{ddd}, 17.98 .91 .5)$ & \multicolumn{4}{c}{$2.55(\mathrm{ddd}, 17.98 .81 .4)$} & \\
$12 \mathrm{a}$ & $1.98 \mathrm{~m}$ & 27.6 & $1.98-1.94 \mathrm{~m}$ & 27.6 \\
$12 \mathrm{~b}$ & $2.05 \mathrm{~m}$ & $2.04(\mathrm{dddd}, 19.18 .84 .01 .7)$ & \\
13 & $4.98 \mathrm{~m}$ & 70.5 & $4.98(\mathrm{dqd}, 7.36 .33 .0)$ & 70.5 \\
14 & $1.27(\mathrm{~d}, 6.3)$ & 19.6 & $1.27(\mathrm{~d}, 6.3)$ & 19.6 \\
$1^{\prime} \mathrm{a}$ & $2.52(\mathrm{dd}, 17.66 .3)$ & 40.5 & $2.53(\mathrm{dd}, 17.66 .3)$ & 40.5 \\
$1^{\prime} \mathrm{b}$ & $3.12(\mathrm{dd}, 17.67 .8)$ & & $3.13(\mathrm{dd}, 17.67 .7)$ & \\
$2^{\prime}$ & & 197.6 & & \\
$3^{\prime}$ & $6.09(\mathrm{dq}, 15.81 .6)$ & 131.5 & $6.09(\mathrm{dq}, 15.91 .8)$ & 131.5 \\
$4^{\prime}$ & $6.87(\mathrm{dd}, 15.86 .8)$ & 143.7 & $6.87(\mathrm{dq}, 15.96 .8)$ & 143.7 \\
$5^{\prime}$ & $1.89(\mathrm{dd}, 6.81 .6)$ & 18.3 & $1.90(\mathrm{dd}, 6.81 .8)$ & 18.4 \\
\hline
\end{tabular}


8. NMR spectrum of synthesized compounds
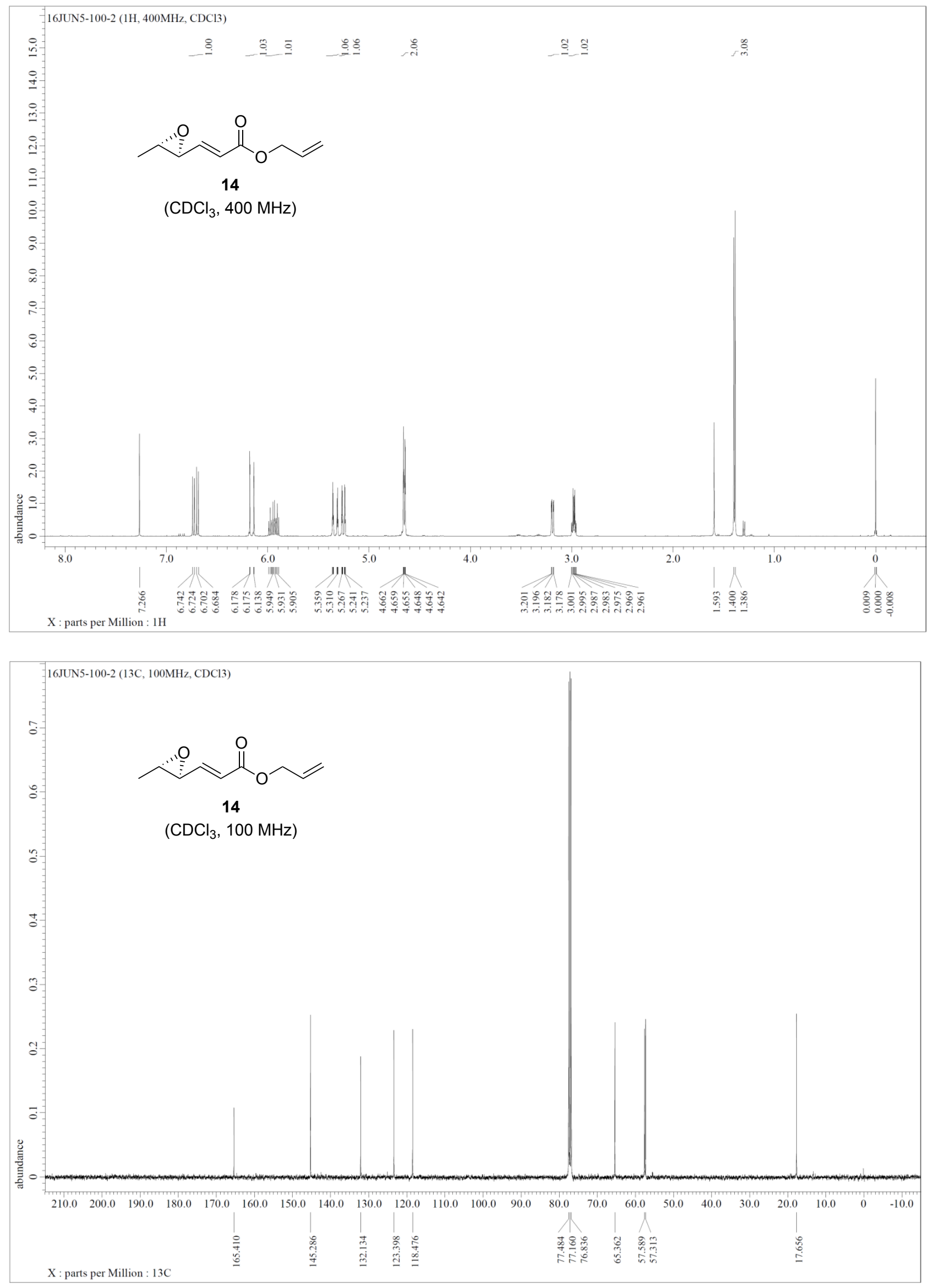

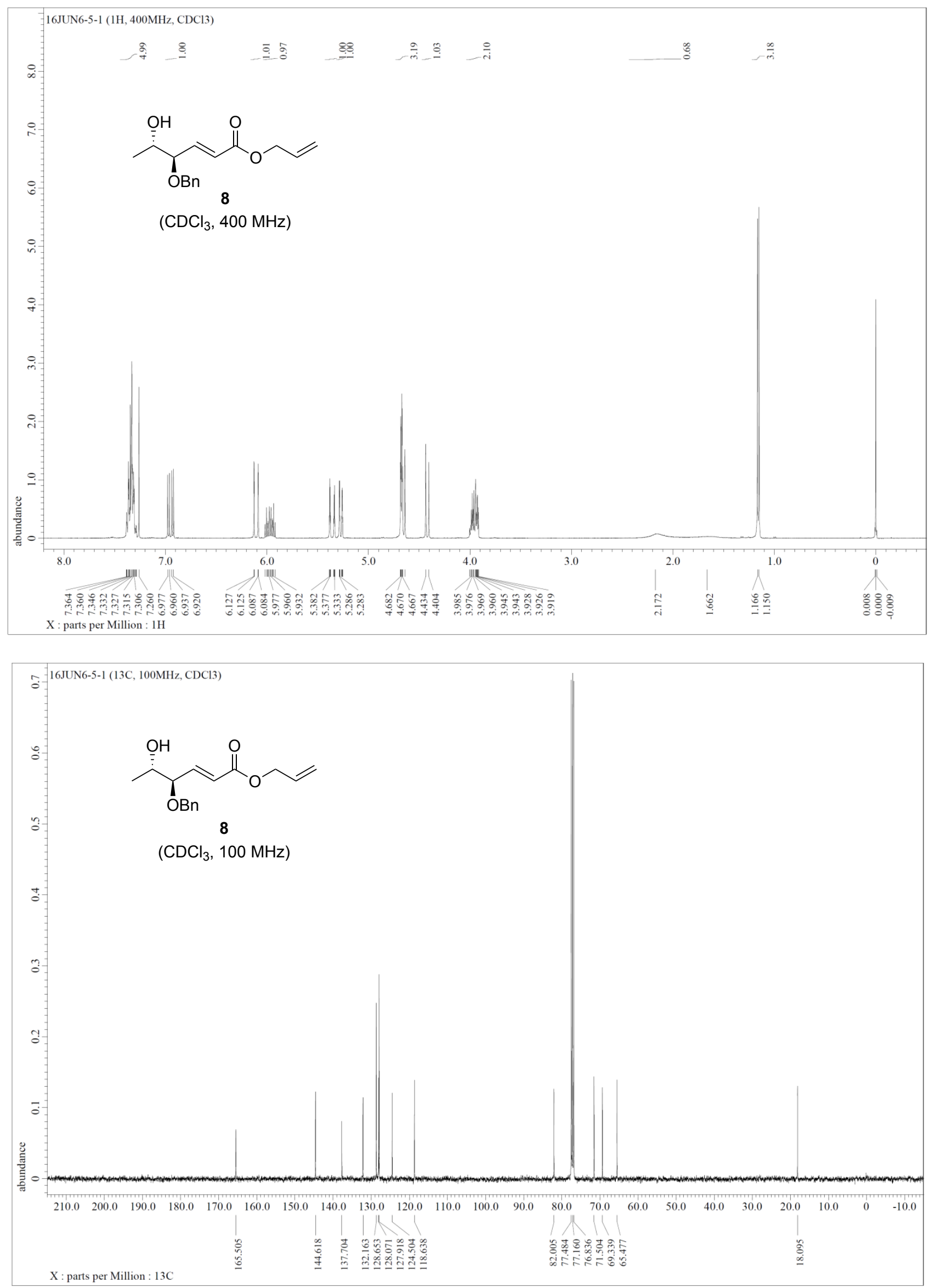

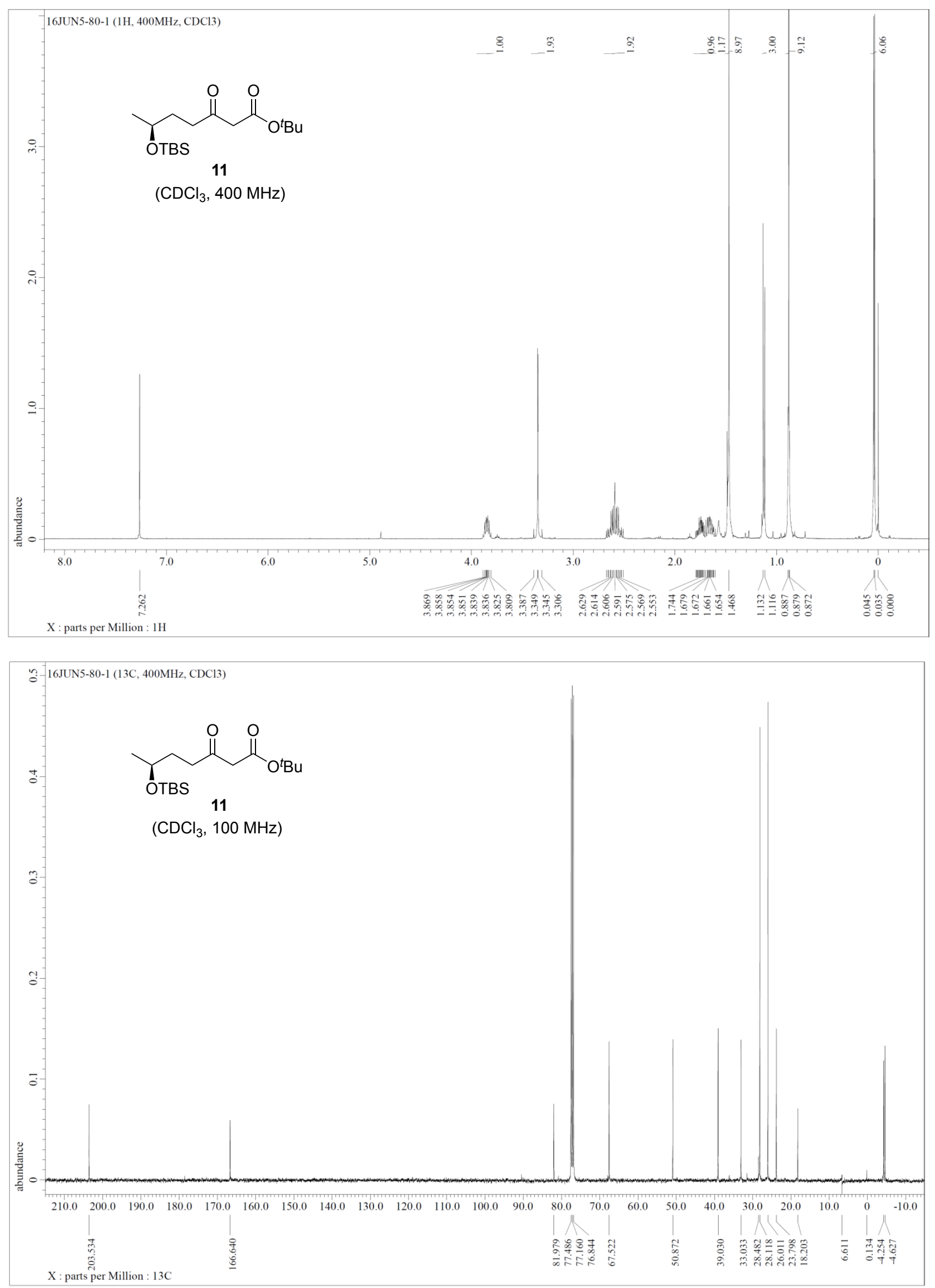

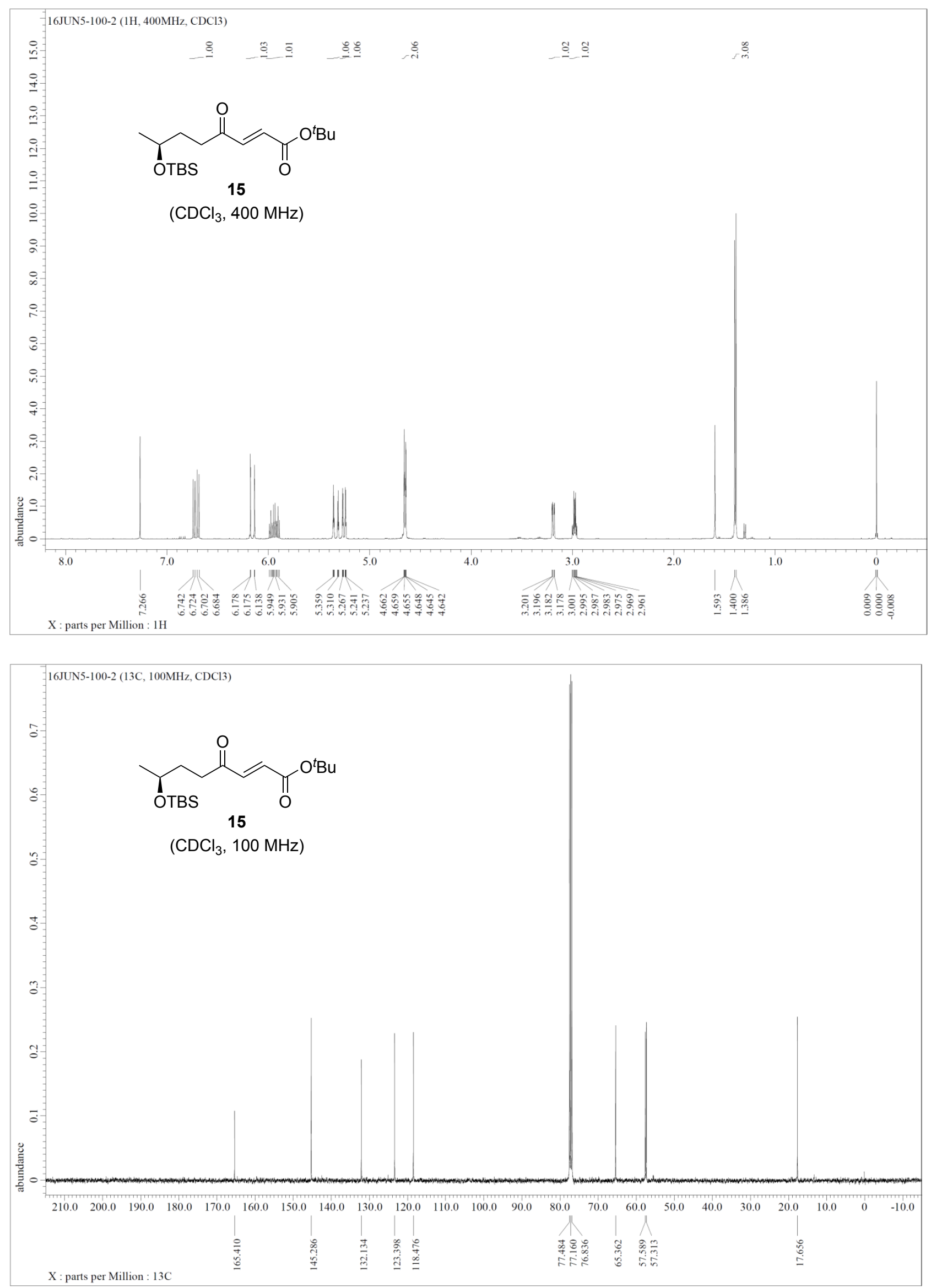

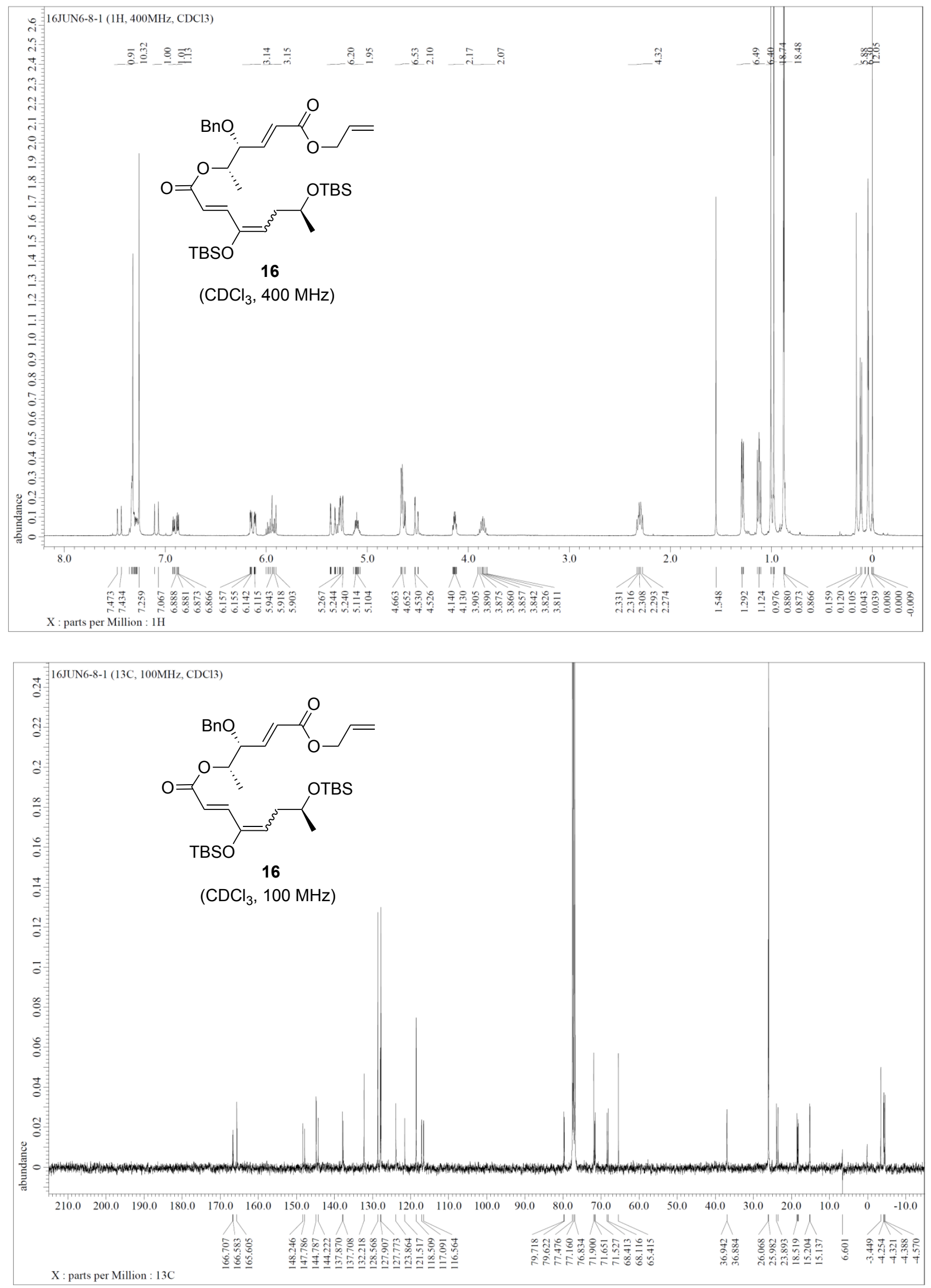

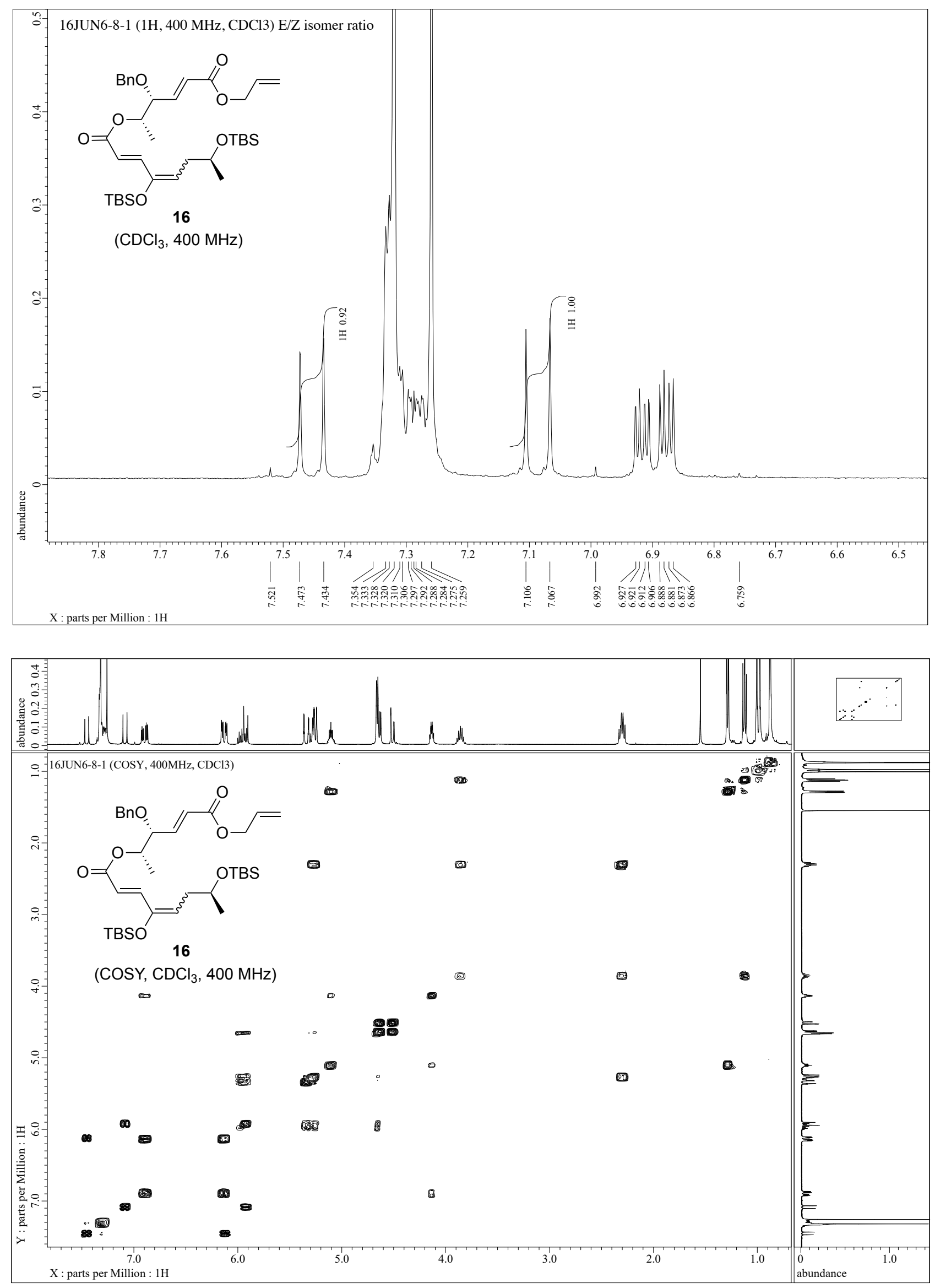

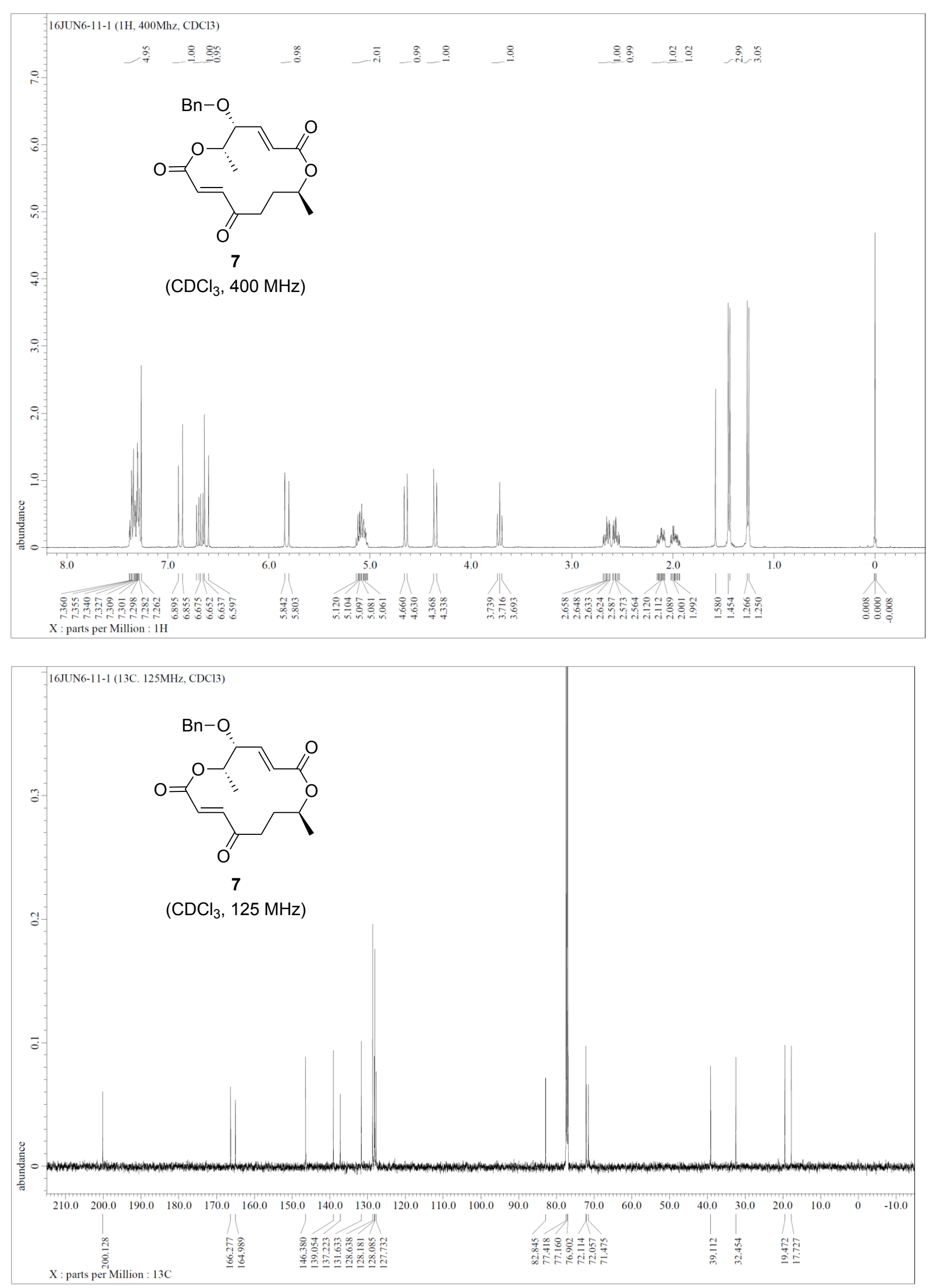

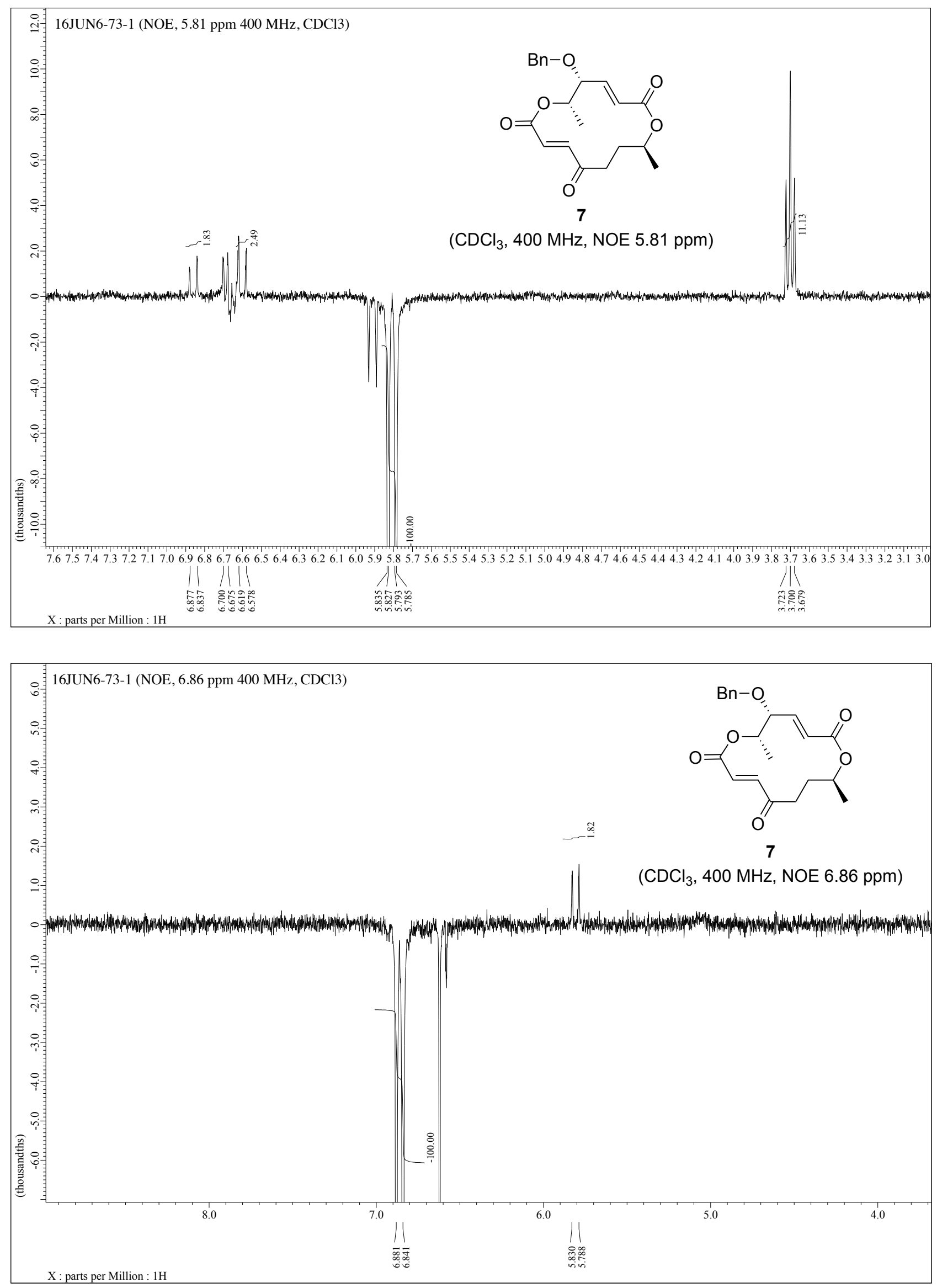

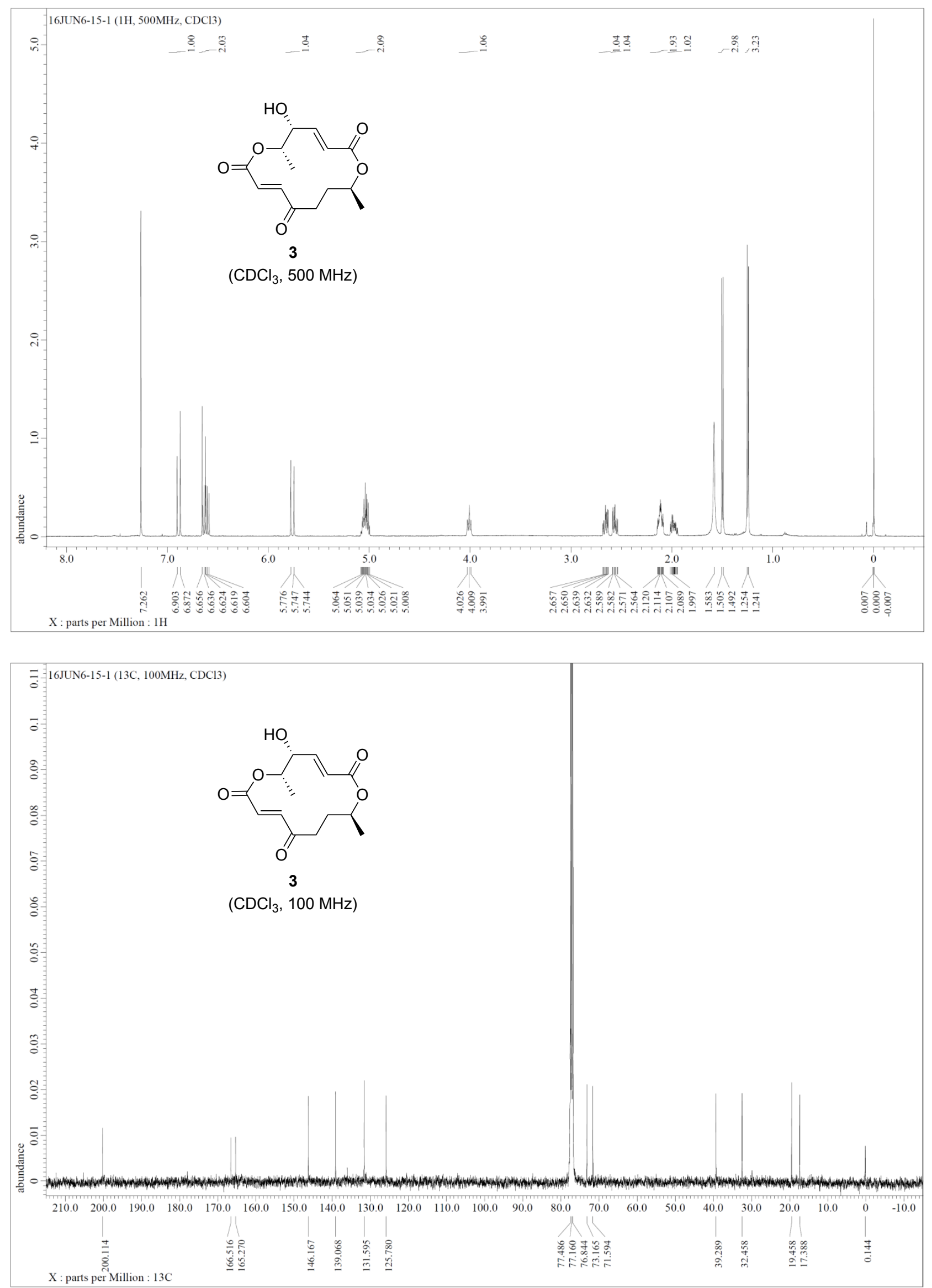

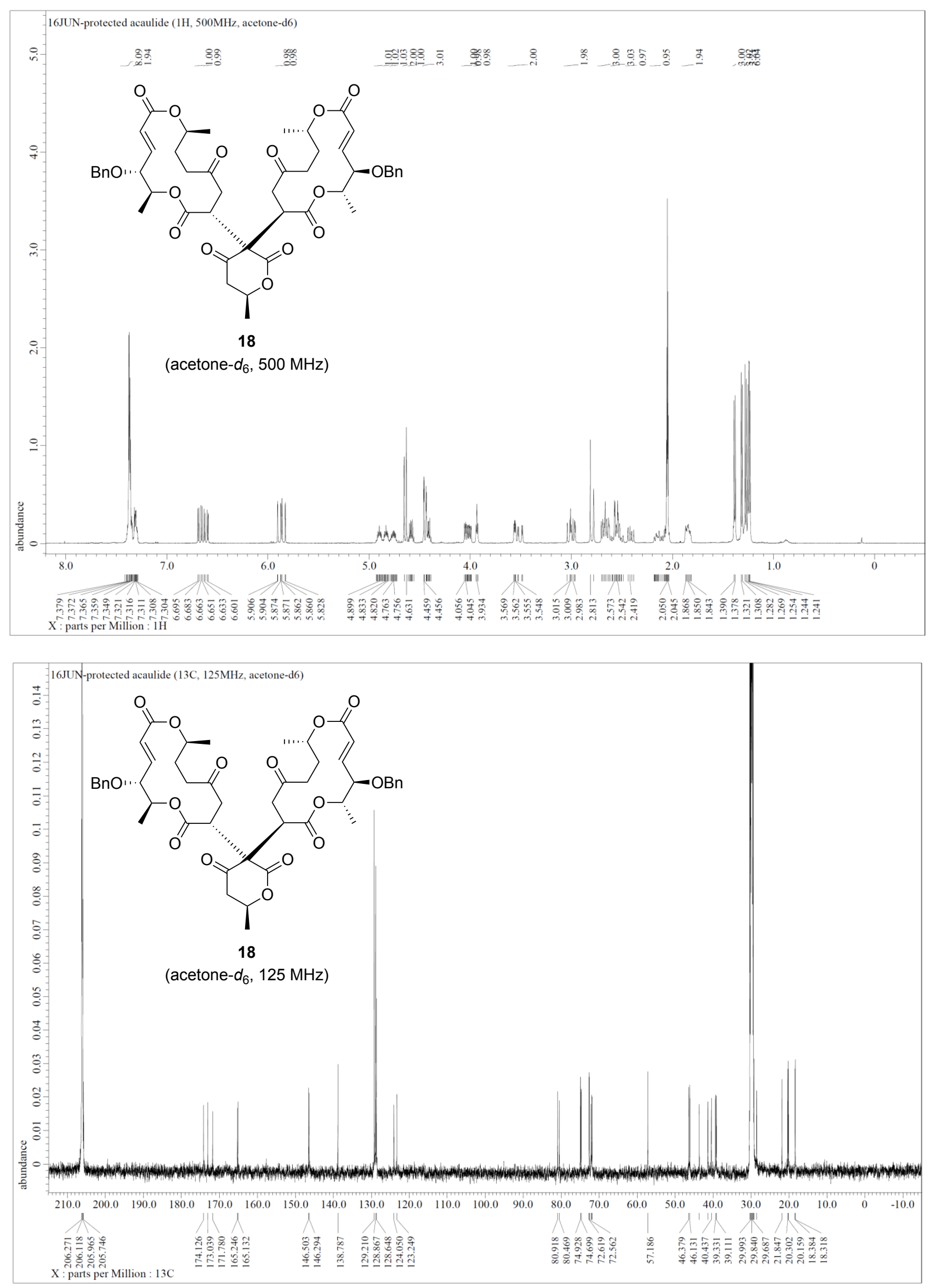

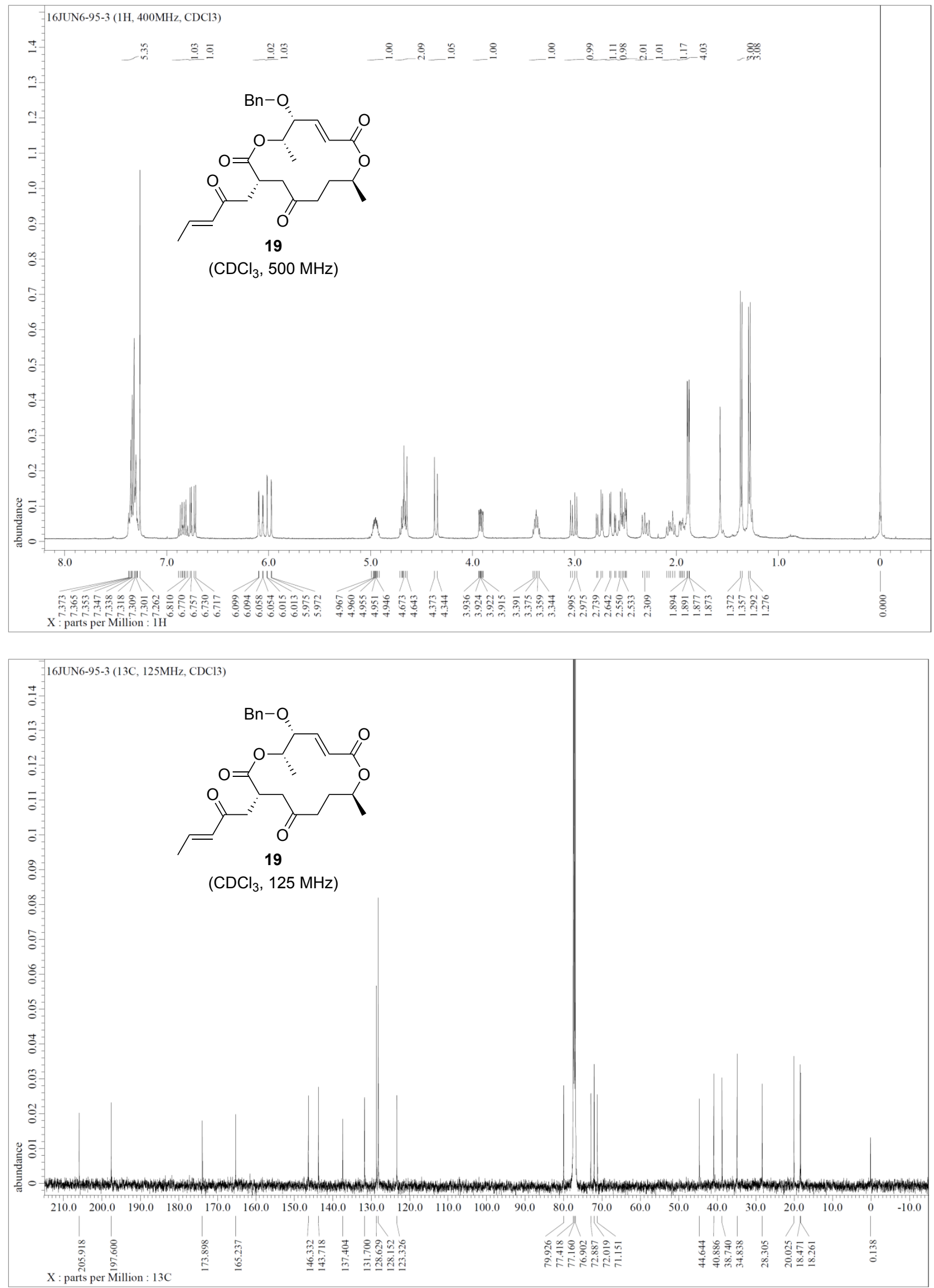

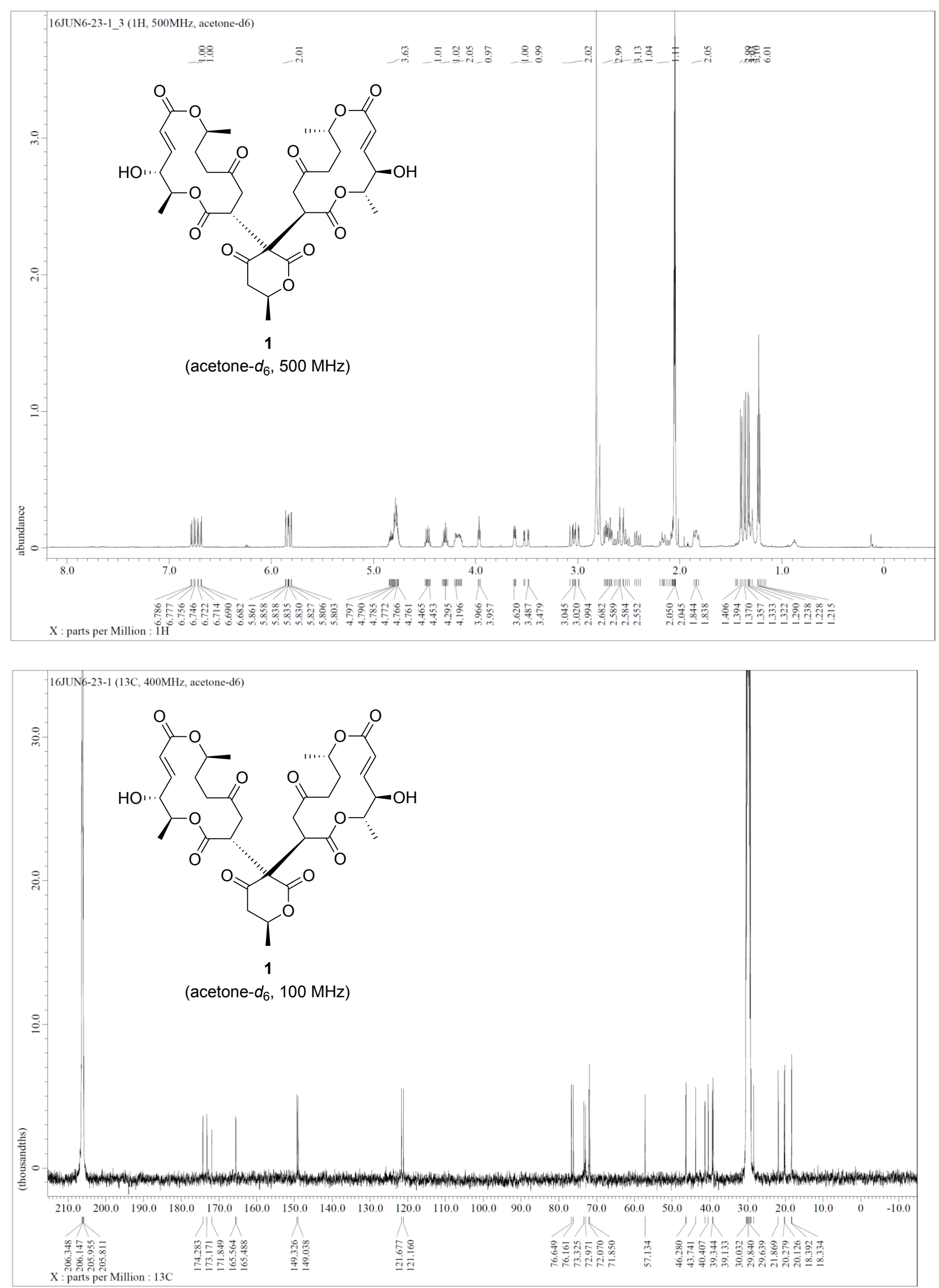

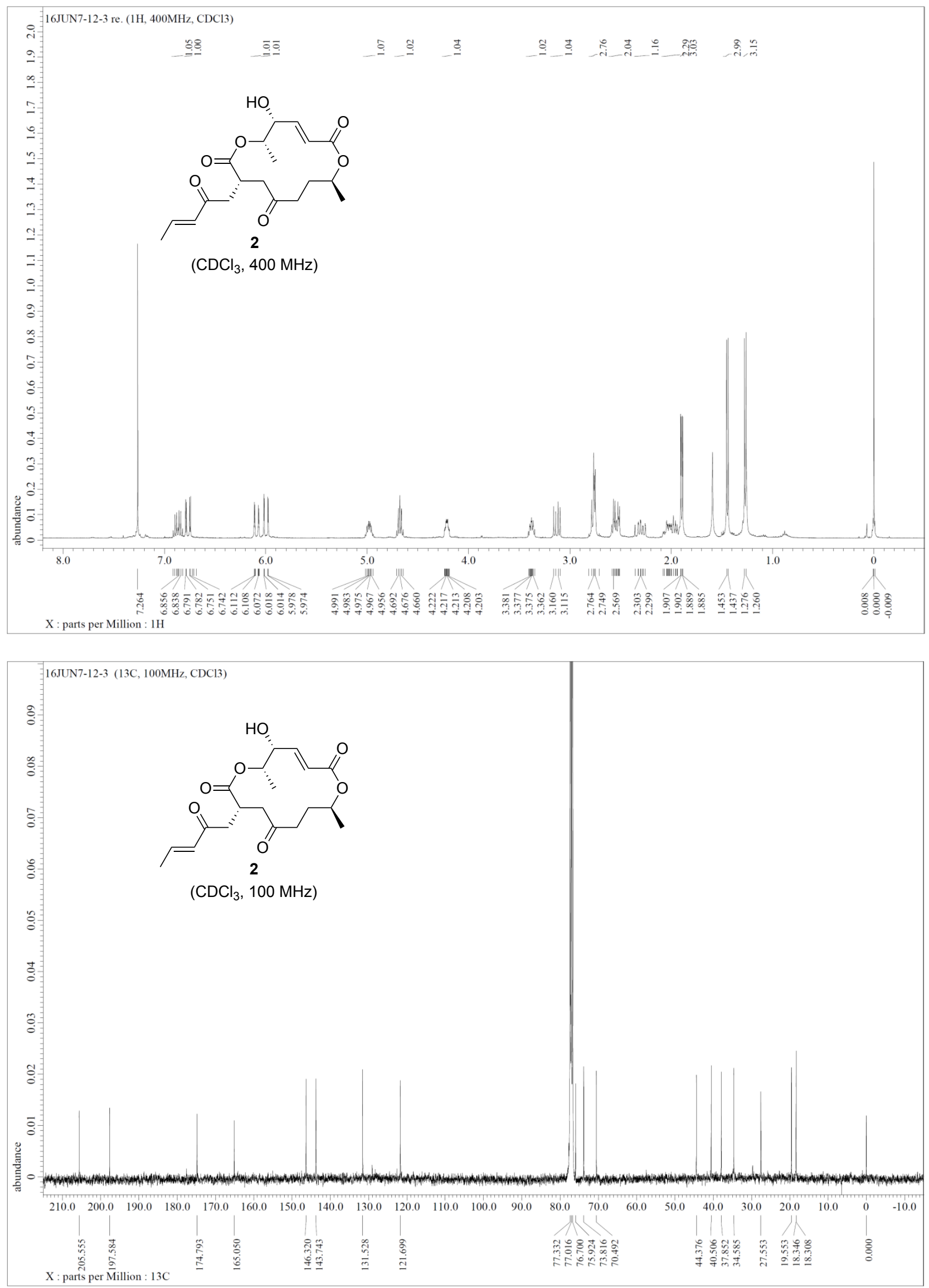


\section{References}

1) T. T. Wang, Y. J. Wei, H. M. Ge, R. H. Jiao, R. X. Tan, Org. Lett. 2018, $20,1007$. 